\title{
Mössbauer parameters of Fe-related defects in group-IV semiconductors: first principles calculations
}

\author{
E. Wright, ${ }^{1}$ J. Coutinho, ${ }^{1, \text { a) }}$ S. Öberg, ${ }^{2}$ and V. J. B. Torres ${ }^{1}$ \\ 1) Department of Physics and I3N, University of Aveiro, Campus Santiago, 3810-193 Aveiro, \\ Portugal \\ ${ }^{2)}$ Department of Engineering Sciences and Mathematics, Luleå University of Technology, Luleå S-97187, \\ Sweden
}

\begin{abstract}
We employ a combination of pseudopotential and all-electron density functional calculations, to relate the structure of defects in supercells to the isomer shifts and quadrupole splittings observed in Mössbauer spectroscopy experiments. The methodology is comprehensively reviewed and applied to the technologically relevant case of iron-related defects in silicon, and to other group-IV hosts to a lesser degree. Investigated defects include interstitial and substitutional iron, iron-boron pairs, iron-vacancy and iron-divacancy. We find that in general, agreement between the calculations and Mössbauer data is within a $10 \%$ error bar. Nonetheless, we show that the methodology can be used to make accurate assignments, including to separate peaks of similar defects in slightly different environments.
\end{abstract}

Keywords: Silicon, Iron, Defect levels, Mössbauer effect

\section{INTRODUCTION}

The ubiquitous nature of iron in silicon feedstock, in the Si melt and in as-grown Si crystals, combined with its high diffusivity and its strong carrier recombination power (particularly in p-type $\mathrm{Si}$ ), make Fe one of the most feared contaminants in electronic- and solar-grade silicon. In fact, the concentration of atomically dispersed $\mathrm{Fe}$ in solar-Si must be kept below a tolerance threshold of only $10^{12} \mathrm{~cm}^{-3}$ to ensure minority carrier lifetimes $\tau \gtrsim 1 \mu \mathrm{s}{ }^{1}$ This is achieved by storing Fe impurities away from active regions in the form of less harmful precipitates with up to several $\mu \mathrm{m}$ in diameter, which in turn poses the latent threat of particle dissolution. ${ }^{2}$ For further details on the subject of iron in silicon the reader is directed to the seminal reviews of Istratov, Hieslmair and Weber. ${ }^{3,4}$

When dissolved in a Si crystal, Fe atoms occur mostly as interstitial impurities $\left(\mathrm{Fe}_{\mathrm{i}}\right)$ occupying tetrahedral interstitial sites. This defect is relatively well understood, and spectroscopic signals obtained through electron paramagnetic resonance (EPR), electron-nuclear double resonance, ${ }^{5-7}$ deep-level transient spectroscopy (DLTS), ${ }^{8,9}$ emission channeling, ${ }^{10,11}$ and Mössbauer spectroscopy (MS) ${ }^{12,13}$ have been reported extensively. Interstitial $\mathrm{Fe}$ in $\mathrm{Si}$ becomes mobile above roomtemperature. In p-type material it diffuses as a positively charged ion, being readily trapped by negatively charged acceptors to form Fe-acceptor pairs. ${ }^{14}$ Two types of iron-acceptor pairs have been reported, namely one with trigonal symmetry and another with orthorhombic symmetry, corresponding to stable and metastable configurations, respectively. ${ }^{3,15-17}$ Based on the fully reversible $\mathrm{Fe}_{\mathrm{i}}^{+}+\mathrm{B}_{\mathrm{s}}^{-} \leftrightarrows \mathrm{Fe}_{\mathrm{i}} \mathrm{B}_{\mathrm{s}}$ reaction, Zoth and Bergholz ${ }^{18}$ proposed a method to quickly estimate the total concentration of $\mathrm{Fe}_{\mathrm{i}}$ in $\mathrm{Si}$ samples with a sensitivity of

a) Electronic mail: jose.coutinho@ua.pt
$10^{11} \mathrm{~cm}^{-3}$, conferring significant technological relevance to Fe-acceptor pairs.

While it is consensual that iron impurities occupy interstitial sites under equilibrium conditions, there is convincing evidence for the existence of substantial concentrations of substitutional $\mathrm{Fe}\left(\mathrm{Fe}_{\mathrm{s}}\right)$ provided by emission channeling ${ }^{10,11}$ and Mössbauer spectroscopy. ${ }^{19-24}$ However, and despite many attempts, powerful techniques like EPR or DLTS have not detected a signal that can be unambiguously assigned to $\mathrm{Fe}_{\mathrm{s}}$. This is rather puzzling, as theory predicts $\mathrm{Fe}_{\mathrm{s}}$ to be a paramagnetic deep acceptor in the negative charge state. ${ }^{25}$ Since channeling measurements invariably involve implantation of radioactive probe ions (followed by thermal anneals), it seems clear that the presence of $\mathrm{Fe}_{\mathrm{s}}$ could result from the interaction between $\mathrm{Fe}_{\mathrm{i}}$ and vacancies. The same argument can be applied to Mössbauer experiments, where Si vacancies produced either by high-temperature annealing/quenching or by the implantation of precursor isotopes (e.g. ${ }^{57} \mathrm{Mn}^{+}$), could interact with $\mathrm{Fe}_{\mathrm{i}}$, ending up with $\mathrm{Fe}_{\mathrm{s}}$ defects. However, Mössbauer experiments where Fe was simply introduced by vacuum-deposition of an Fe layer on the surface of samples which were not heat treated, apparently shows a strong $\mathrm{Fe}_{\mathrm{s}}$-related signal at room temperature, presumably without a deliberate introduction of vacancies. ${ }^{26}$

These observations are rather intriguing, particularly considering that Neutron Activation Analysis (NAA) indicates that the total amount of $\mathrm{Fe}$ closely matches that measured by EPR, ${ }^{27}$ assigned to the spin- 1 state of neutral $\mathrm{Fe}_{\mathrm{i}}$. In these experiments $\mathrm{Fe}$ was introduced by evaporation, followed by in-diffusion at $900^{\circ} \mathrm{C}-1200^{\circ} \mathrm{C}$ and quenching to minimize Fe-precipitation. Furthermore, the site-independent enthalpy of formation per iron atom in Si obtained from NAA $(\Delta H=2.94 \mathrm{eV})$ compares well with the same quantity measured by EPR $(\Delta H=2.87 \mathrm{eV})$, which is only sensitive to $\mathrm{Fe}_{\mathrm{i}}$. Such agreement provides compelling evidence that, under thermal equilibrium, the vast majority of isolated Fe impuri- 
ties occupy interstitial sites.

Theoretical modeling, namely electronic structure calculations based on density functional theory, is a powerful way of studying defects and their electronics. The (apparent) contradictions described above call for clarification, particularly in regard to the Mössbauer parameters of Fe-related defects in $\mathrm{Si}$, as well as the equilibrium concentration of $\mathrm{Fe}_{\mathrm{s}}$ (relative to that of $\mathrm{Fe}_{\mathrm{i}}$ ). Mössbauer spectroscopy is based on the recoilless emission and absorption of $\gamma$-radiation from and by the nuclei of bound atoms. ${ }^{28}$ In the absence of a magnetic field at the nucleus, the relevant interactions are electric monopolar and quadrupolar, which are quantified by the Isomer Shift (IS or $\delta$ ) and the Quadrupole Splitting (QS or $\Delta$ ) respectively. ${ }^{28-30}$ In essence, these two parameters are sensitive to the magnitude of the contact electron density and to the non-sphericity of the density surrounding the Mössbauer nucleus $\left({ }^{57} \mathrm{Fe}\right.$ in this case).

Motivated by the impact of $\mathrm{Fe}$ and its complexes on Si based technology, ${ }^{57} \mathrm{Fe}$ MS has been used to study the location, diffusivity and electronic activity of elemental Fe impurities. ${ }^{3,20,31,32}$ A summary of experimental and calculated IS values for $\mathrm{Fe}_{\mathrm{i}}$ and $\mathrm{Fe}_{\mathrm{s}}$ defects in $\mathrm{Si}$ and other group IV semiconductors is presented in Table I. Consistent agreement between theoretical and experimental values of $\delta$ has enabled the identification of $\mathrm{Fe}_{\mathrm{i}}$ and $\mathrm{Fe}_{\mathrm{s}}$ defects in $\mathrm{Si}$, where $\delta\left(\mathrm{Fe}_{\mathrm{s}}\right) \simeq-0.04 \mathrm{~mm} / \mathrm{s}$ and $\delta\left(\mathrm{Fe}_{\mathrm{i}}\right) \simeq 0.8 \mathrm{~mm} / \mathrm{s}^{12,13,33}$ In $\mathrm{Ge}$, the picture also appears to be well established, with experiments and theory suggesting $\delta\left(\mathrm{Fe}_{\mathrm{i}}\right) \simeq 0.8 \mathrm{~mm} / \mathrm{s}$ and a small, albeit positive $\delta\left(\mathrm{Fe}_{\mathrm{s}}\right) \simeq 0.06 \mathrm{~mm} / \mathrm{s}{ }^{34} \mathrm{In}$ diamond, and despite good agreement between the calculated value and the $\delta=0.22 \mathrm{~mm} / \mathrm{s}$ resonance assigned to $\mathrm{Fe}_{\mathrm{i}}$, calculations for $\mathrm{Fe}_{\mathrm{s}}$ severely underestimate the experimental result by a factor ranging between 5 and 10. Finally, in $\mathrm{SiC}$ there are two possible sites for $\mathrm{Fe}_{\mathrm{i}}$ and $\mathrm{Fe}_{\mathrm{S}}$ defects. The interstitial impurity can have Si or C first neighbors $\left(\mathrm{Fe}_{\mathrm{i}, \mathrm{Si}}\right.$ or $\mathrm{Fe}_{\mathrm{i}, \mathrm{C}}$ respectively), while substitutional $\mathrm{Fe}$ can replace $\mathrm{Si}$ or $\mathrm{C}$ atoms $\left(\mathrm{Fe}_{\mathrm{Si}}\right.$ or $\mathrm{Fe}_{\mathrm{C}}$ respectively). While the agreement between theory and experiments is reasonable, only a single resonance has been reported for substitutional $\mathrm{Fe}$, although two peaks are theoretically predicted. Interestingly, the overall trend of the MS peaks in $\mathrm{Si}$, Ge, Diamond and $\mathrm{SiC},{ }^{34-36}$ is characterized by a linear increase of $\delta\left(\mathrm{Fe}_{\mathrm{s}}\right)$ and $\delta\left(\mathrm{Fe}_{\mathrm{i}}\right)$ with the distance between $\mathrm{Fe}$ and its first neighbors, as depicted in Figure 2 of Ref. 37.

The electronic activity of $\mathrm{Fe}_{\mathrm{s}}$ and $\mathrm{Fe}_{\mathrm{i}}$ defects in $\mathrm{Si}$ has been studied using MS by varying the type and concentration of dopants in the samples. ${ }^{12,26,42}$ However, conflicting MS parameters have been reported for some elemental $\mathrm{Fe}$ defects in Si. The ISOLDE consortium reported a $\delta\left(\mathrm{Fe}_{\mathrm{s}}\right)=-0.04 \mathrm{~mm} / \mathrm{s}$ peak which is effectively independent of the dopant type and concentration, and was therefore assigned to the neutral charge state of substitutional iron $\left(\mathrm{Fe}_{\mathrm{s}}^{0}\right)$. From the same experiments, neutral and positively charged $\mathrm{Fe}_{\mathrm{i}}$ defects were assigned to resonances at $\delta\left(\mathrm{Fe}_{\mathrm{i}}^{0}\right)=$ $0.72 \mathrm{~mm} / \mathrm{s}$ and $\delta\left(\mathrm{Fe}_{\mathrm{i}}^{+}\right)=0.78 \mathrm{~mm} / \mathrm{s}$ in n-type and $\mathrm{p}$ -
Table I. Summary of experimental (Exp.) and calculated (Calc.) isomer shifts for $\mathrm{Fe}_{i}$ and $\mathrm{Fe}_{\mathrm{s}}$ defects in group IV semiconductors, in $\mathrm{mm} / \mathrm{s}$. For $\mathrm{SiC}$, distinct rows are used for the values of $\mathrm{Fe}$ with $\mathrm{Si}\left(\mathrm{Fe}_{\mathrm{i}, \mathrm{Si}} / \mathrm{Fe}_{\mathrm{C}}\right)$ and $\mathrm{C}\left(\mathrm{Fe}_{\mathrm{i}, \mathrm{C}} / \mathrm{Fe}_{\mathrm{Si}}\right)$ first neighbors. NA stands for not available.

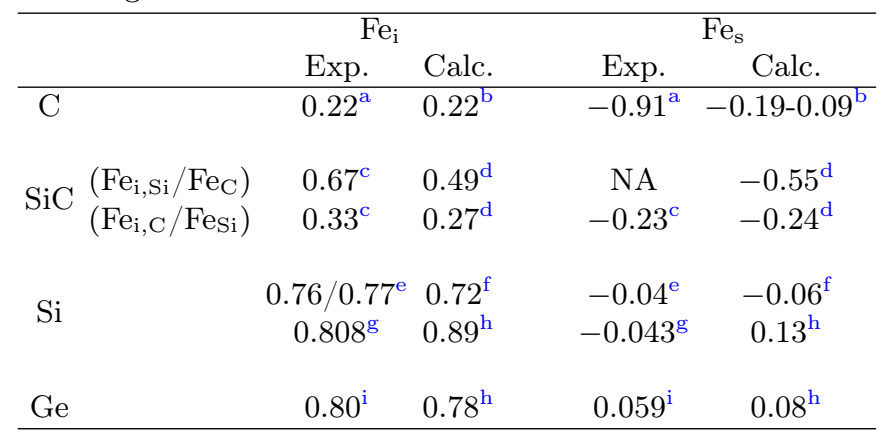

${ }^{\text {a }}$ Ref. 35

b Ref. 38

c Ref. 36

d Corresponding to $6 \mathrm{H}-\mathrm{SiC}$ Ref. 39

e Varies with doping, cf. Ref. 12

${ }^{\mathrm{f}}$ Ref. 40

g Ref. 13

${ }^{\mathrm{h}}$ Ref. 41

${ }^{\text {i }}$ Ref. 34

type material, respectively. ${ }^{12,42}$ More recently, and for the same defects, Yoshida and his group reported IS values of $\delta\left(\mathrm{Fe}_{\mathrm{s}}^{0}\right) \simeq-0.17 \mathrm{~mm} / \mathrm{s}, \delta\left(\mathrm{Fe}_{\mathrm{i}}^{0}\right)=0.40 \mathrm{~mm} / \mathrm{s}$ and $\delta\left(\mathrm{Fe}_{\mathrm{i}}^{+}\right)=0.80 \mathrm{~mm} / \mathrm{s}^{26,43}$

Other defects were tentatively assigned using MS, namely a quadrupole-split doublet labeled $\mathrm{Fe}_{\mathrm{N}}$ with $\Delta\left(\mathrm{Fe}_{\mathrm{N}}\right)=0.51 \mathrm{~mm} / \mathrm{s}$ and $\delta\left(\mathrm{Fe}_{\mathrm{N}}\right)=0.43 \mathrm{~mm} / \mathrm{s}$, assigned to an iron-vacancy $\left(\mathrm{Fe}_{\mathrm{i}} \mathrm{V}\right)$ pair, ${ }^{12}$ and another doublet labeled $\mathrm{Fe}_{\mathrm{D}}$ which has been associated to $\mathrm{Fe}$ in regions damaged by the ion-implantation process, with $\Delta\left(\mathrm{Fe}_{\mathrm{D}}\right)=1.02 \mathrm{~mm} / \mathrm{s}$ and $\delta\left(\mathrm{Fe}_{\mathrm{D}}\right)=0.33 \mathrm{~mm} / \mathrm{s}^{33}$

$A b$-initio calculations of Mössbauer parameters have played an important role in the interpretation and validation of experimental data. For the particular case of defects in semiconductors, these calculations have been hampered by the fact that solid state effects can only be accounted for if defects are embedded in a sufficiently large supercell or cluster. Owing to the computational effort involved, few attempts to calculate the IS and QS of defects were made, ${ }^{38,41}$ which invariably implied several limitations and approximations like the use of small supercells, a local or semi-local approach to the electronic exchange-correlation interactions, or a non-relativistic treatment of core states. However, statestate-of-the-art calculations employing (linearized) augmented plane-wave methods (eventually complemented by local orbitals), can account for relativistic core and valence states, as well as anisotropy effects in the core potentials. Encouraging results have been recently reported, including the calculation of $\delta\left(\mathrm{Fe}_{\mathrm{s}}\right)$ and $\delta\left(\mathrm{Fe}_{\mathrm{i}}\right)$ in $\mathrm{SiC},{ }^{39}$ and for more elaborate Fe-related defects in Si such as Fe-vacancy and Fe-interstitial complexes. ${ }^{40}$ The aim of this work is to review the methodology used to calculate 
Mössbauer parameters from first-principles, and to apply the protocol to a set of relevant Fe defects in Si. In Section II we describe the methodology used to calculate formation energies, electronic levels, contact densities and electric field gradients. We then proceed to calculate the Mössbauer calibration constants (Section IIE). In Sections III and IV we report the results obtained for $\mathrm{Fe}$ defects in Si and other group-IV semiconductors, namely formation energies, electronic levels and Mössbauer parameters, followed by our conclusions in Section V.

\section{THEORETICAL METHOD}

All calculations were carried out within density functional theory, ${ }^{44,45}$ adopting the generalized gradient approximation to the exchange-correlation potential among electrons as proposed by Perdew, Burke and Ernzerhof (PBE) ${ }^{46,47}$ Mössbauer spectroscopy probes the shape of the electron density at nuclear sites, depending on both core and valence states. This means that the calculation of the Mössbauer parameters requires an accurate description of the coupling between core and valence states, and therefore involves solving an all-electron problem. To this end, contact densities $\bar{n}$ (averaged within the nuclear volume) and electric field gradients $V_{i j}$ (EFG) were calculated using the full-potential all-electron ELK code, employing a basis of augmented plane-waves plus local orbitals $(\mathrm{APW}+\mathrm{lo}) .{ }^{48}$ On the other hand, for the purpose of describing the geometry and chemistry of $\mathrm{Fe}$ defects, core electrons can be safely frozen and considered as if they were bound to free atoms. In this case, ground state structures of supercells with and without defects, their respective energies and defect levels were obtained using the planewave VASP code $^{49-52}$ with core states treated within the projector augmented-wave (PAW) method. ${ }^{53,54}$ Supercell structures obtained within the PAW method were subsequently plugged into the allelectron code, in order to extract $\bar{n}$ and $V_{i j}$ values for the Fe defects.

The band structures were sampled over $\Gamma$-centered $N_{1} \times N_{2} \times N_{3}$ grids of k-points along the $\mathbf{b}_{1}, \mathbf{b}_{2}$ and $\mathbf{b}_{3}$ reciprocal lattice vectors, or MP- $N_{1} \times N_{2} \times N_{3}$ in abbreviated form. ${ }^{55}$ The grids employed for each case are reported throughout the text, alongside a description of the corresponding system.

\section{A. PAW calculations}

For these calculations, PAW potentials (constructed with a specific valence configuration) for $\mathrm{Fe}\left(3 s^{2} 3 p^{6} 3 d^{7} 4 s^{1}\right), \mathrm{B}\left(2 s^{2} 2 p^{1}\right), \mathrm{C}\left(2 s^{2} 2 p^{2}\right), \mathrm{Si}\left(3 s^{2} 3 p^{2}\right)$ and $\operatorname{Ge}\left(4 s^{2} 4 p^{2}\right)$ were considered. Kohn-Sham valence states were expanded in plane-waves with kinetic energies up to $E_{\text {cut }}=450 \mathrm{eV}$. The electronic spin treatment was collinear and allowed to relax. Atomic coordinates were relaxed using either a conjugate-gradient method or a quasi-Newton algorithm, until the maximum force acting on atoms was not larger than $2.5 \times 10^{-3} \mathrm{eV} / \AA$.

Iron-related point defects were inserted into $64-$ and 216-atom supercells with a simple cubic lattice. Unless otherwise specified, isomer shifts and quadrupole splittings were calculated for Fe defects in the smaller supercells, while other defect properties (formation energies, electrical levels, transformation barriers) were calculated using the larger supercells. The lattice parameters were those that minimized the energy of bulk primitive cells, namely $a_{\mathrm{C}}=3.5736 \AA, a_{\mathrm{Si}}=5.4687 \AA, a_{\mathrm{Ge}}=5.7829 \AA$ and $a_{\mathrm{SiC}}=4.3785 \AA$, for diamond, Si, Ge and $3 \mathrm{C}-\mathrm{SiC}$ (cubic polytype), respectively. As expected from the use of the PBE functional, these figures overestimate (by less than $1 \%$, except for Ge where the deviation is about $2 \%$ ) the corresponding experimental lattice parameters of $3.5668 \AA, 5.4310 \AA, 5.6579 \AA$ and $4.3596 \AA{ }^{56}$ For the case of Fe defects in Si-rich SiGe alloys, the host consisted of a $\mathrm{Si}$ supercell with one substitutional Ge atom. The lattice parameter $a_{\mathrm{SiGe}}=5.4736 \AA$ was scaled linearly between $a_{\mathrm{Si}}$ and $a_{\mathrm{Ge}}$ assuming a Vegard alloying regime. The band structure of all defective supercells was integrated by using MP- $2^{3} \mathbf{k}$-point grids, totaling 8 reducible points. For all group-IV semiconductor primitive cells we employed MP- $12^{3} \mathbf{k}$-point grids.

Total energies and energy differences were tested as a function of $E_{\text {cut }}$ and $\mathbf{k}$-point sampling in order to ensure that the latter converged within $1 \mathrm{meV}$. For the sake of example, the dashed line depicted in Figure 1(a) represents the variation of the total energy per formula unit (in $\mathrm{eV} /$ f.u.) of $\alpha-\mathrm{FeSi}_{2}$ as a function of the plane-wave cut-off energy. Specifically, it represents $\delta E_{\alpha-\mathrm{FeSi}_{2}}=$ $\left|E_{\alpha-\mathrm{FeSi}_{2}}\left(E_{\text {cut }}\right)-E_{\alpha-\mathrm{FeSi}_{2}}(600 \mathrm{eV})\right|$, where $E_{\alpha-\mathrm{FeSi}_{2}}\left(E_{\text {cut }}\right)$ is the energy of crystalline $\alpha-\mathrm{FeSi}_{2}$ as a function of $E_{\text {cut }}$. Also in the same figure, the solid line shows the variation of the energy difference (in $\mathrm{eV} /$ f.u.) between the $\alpha-\mathrm{FeSi}_{2}$ and $\gamma-\mathrm{FeSi}_{2}$ phases as a function of $E_{\text {cut }}$, with respect to analogous calculations with $E_{\text {cut }}=600 \mathrm{eV}$. While the total energy converges within $10 \mathrm{meV}$ around $E_{\text {cut }} \gtrsim 400 \mathrm{eV}$, the energy difference is at least one order of magnitude more accurate for the same value of $E_{\text {cut }}$. The Brillouin zone (BZ) integration for the $\alpha$ and $\gamma$ phases of $\mathrm{FeSi}_{2}$ was carried out on $\mathrm{MP}-16^{2} \times 14$ and $\mathrm{MP}-16^{3}$ grids of $\mathbf{k}$-points, respectively.

\section{B. APW+lo calculations}

The contact densities and EFG tensors for Fe nuclei were calculated using the APW+lo method. ${ }^{57,58} \mathrm{We}$ addressed the all-electron problem self-consistently within density functional theory. Core states were treated relativistically by solving the spherical Dirac equation, while valence states were expanded in APW functions subject to the full potential. The APWs are dualrepresentation functions that divide the cell volume into two regions, namely a muffin-tin (MT) region comprising non-overlapping spheres with radius $R_{\mathrm{MT}, N}$ centered at 


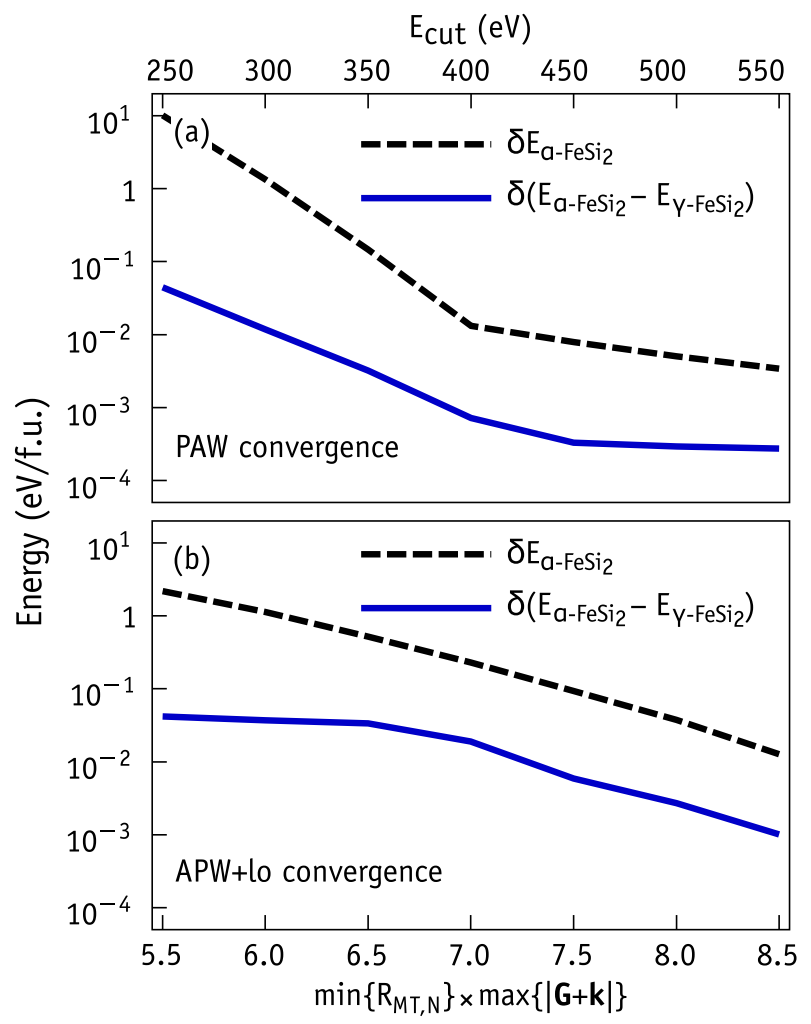

Figure 1. Convergence of the total energy of $\alpha-\mathrm{FeSi}_{2}$ (dashed line) against the convergence of the energy difference between $\alpha-\mathrm{FeSi}_{2}$ and $\gamma-\mathrm{FeSi}_{2}$ crystals (solid line) as a function of the basis size. (a) PAW and (b) APW+lo calculations. Energies are in $\mathrm{eV}$ per formula unit (eV/f.u.). The values were calculated with respect to well converged results with plane wave cut-offs for the valence wavefunctions set at $E_{\text {cut }}=600 \mathrm{eV}$ for the PAW calculations and $E_{\text {cut }}=250 \mathrm{eV}$ (corresponding to $\left.\min \left\{R_{\mathrm{MT}, N}\right\} \times \max \{|\mathbf{G}+\mathbf{k}|\}=9.0\right)$ in the $\mathrm{APW}+$ lo calculations. See text for further details and definitions.

each nuclear coordinate $\mathbf{R}_{N}$, and an interstitial (I) region which is basically elsewhere in the volume $\Omega$ of the periodic cell. Electronic states $\psi_{\mathbf{k} \lambda}^{\sigma}(\mathbf{r})$, where $\sigma$ and $\lambda$ denote spin and band index, are then expanded using a basis of augmented plane waves,

$\phi_{\mathbf{G}+\mathbf{k}}(\mathbf{r})= \begin{cases}\sum_{N j l m} a_{\mathbf{G}+\mathbf{k}}^{N j l m} u_{N l}^{(j)}\left(r_{N}, \epsilon_{N j l}\right) Y_{l m}\left(\hat{\mathbf{r}}_{N}\right), & r_{N}<R_{\mathrm{MT}} \\ \Omega^{-1 / 2} \exp [\mathrm{i}(\mathbf{G}+\mathbf{k}) \cdot \mathbf{r}], & \mathbf{r} \in \mathrm{I} .\end{cases}$

Each partial wave function enclosed by the MT sphere results from the product of a spherical harmonic $Y_{l m}$ and the $j$-th energy derivative of the radial solution to the Schrödinger equation for the free atom $N, u_{N l}^{(j)}=$ $\partial^{j} u_{N l} / \partial \epsilon^{j}$, with $l$ and $m$ being the usual angular and magnetic moment quantum numbers. In this work we considered contributions of APWs with $l \leq 8$. Each radial function's derivative $u_{N l}^{(j)}$ depends parametrically on a linearization energy $\epsilon_{N j l}$, and is a function of a local coordinate $\mathbf{r}_{N}=r_{N} \hat{\mathbf{r}}_{N}=\mathbf{r}-\mathbf{R}_{N}$ with origin at the
$N$-th nucleus. The $a_{\mathbf{G}+\mathbf{k}}^{N j l m}$ coefficients are chosen such that each partial wave function matches a plane wave counterpart at the MT/I boundary, where $\mathbf{G}$ and $\mathbf{k}$ are a reciprocal lattice vector and a wave vector within the first BZ (special k-point), respectively. Note that according to this definition, the Linearized APW (LAPW) scheme $^{59}$ is readily available by considering only $u_{N l}$ and its first energy derivative $\partial u_{N l} / \partial \epsilon$ in the partial wave expansion. For each calculation the basis was specified by the condition $\min \left\{R_{\mathrm{MT}, N}\right\} \times \max \{|\mathbf{G}+\mathbf{k}|\}=8$, and the muffin-tin radii for $\mathrm{Fe}, \mathrm{C}, \mathrm{Si}, \mathrm{Ge}, \mathrm{F}, \mathrm{Br}$ and $\mathrm{Ti}$ set to $1.11 \AA, 0.95 \AA, 1.11 \AA, 1.27 \AA, 0.95 \AA, 1.27 \AA$, and $1.27 \AA$, respectively.

Further basis flexibility was conferred to the APWs by adding a set of $l m$-dependent local orbitals centered on each nucleus,

$$
\phi_{\mathrm{lo}}^{N l m}\left(\mathbf{r}_{N}\right)=\sum_{j} a_{\mathrm{lo}}^{N j l m} u_{N l}^{(j)}\left(r_{N}, \epsilon_{N j l}\right) Y_{l m}\left(\hat{\mathbf{r}}_{N}\right),
$$

where the coefficients $a_{\text {lo }}$ are determined by normalization and requiring that $\phi_{\text {lo }}$ functions (and eventually their radial derivatives) vanish at the MT boundary. All basis functions and linearization energies were those provided by the official ELK distribution. The potential (and the electron density) also employed a dual representation. Within the MT region is was expanded using lattice harmonics with angular momentum $l_{\phi} \leq 7$, while across the interstitial region it was expanded in stars of planewaves whose kinetic energies were limited at $E_{\text {cut }, \phi}=1.96 \mathrm{keV}$.

Looking at Figure 1(b) it is clear that for a particular basis specification, and analogously to the PAW calculations, energy differences are about one order of magnitude better converged than the total energies. The figure also shows that under production conditions $\left(\min \left\{R_{\mathrm{MT}, N}\right\} \times \max \{|\mathbf{G}+\mathbf{k}|\}=8\right)$ the energy differences converge within a few meV. The $\gamma$-phase of $\mathrm{FeSi}_{2}$ is metastable with respect to the $\alpha$-phase by $E_{\gamma-\mathrm{FeSi} 2}-$ $E_{\alpha-\mathrm{FeSi} 2}=0.37 \mathrm{eV} /$ f.u. These figures are in agreement with $E_{\gamma-\mathrm{FeSi} 2}-E_{\alpha-\mathrm{FeSi} 2}=0.32 \mathrm{eV} /$ f.u. reported from previous all-electron LAPW calculations. ${ }^{60}$ Other convergence tests showed that total energies and energy differences varied by less than $2 \mathrm{meV}$ and $0.3 \mathrm{meV}$ with potential using $l_{\phi}=9$ and $E_{\text {cut }, \phi}=2.67 \mathrm{keV}$.
potect to more demanding conditions in desction

\section{Calculation of isomer shifts and quadrupole splittings}

For any point $\mathbf{r}$ far from the nucleus, the potential $\phi(\mathbf{r})$ due to a nuclear charge density $\rho_{\mathrm{N}}(\mathbf{r})$ can be represented by a multipolar expansion $\phi \equiv \phi_{0}+\phi_{i}+\ldots+\phi_{N}$. Each of the resulting $\phi_{i}$ terms interacts with the electronic charge density, adding $E_{i}$ energy terms to the total energy. ${ }^{29}$ Since the electric monopole term $\phi_{0}$ does not account for the finite nature of the nucleus, this method can not describe the electronic contact density and its 
contribution to $E_{0}$. Relativistic and perturbative methods have been employed to solve this problem, where $\rho_{\mathrm{N}}$ was described by an equivalent uniformly charged sphere of radius $R_{\mathrm{N}} .{ }^{61}$ Accordingly, by treating the corresponding potential as a perturbation to $\phi_{0}$, a first order energy correction

$$
\Delta E_{0}=\frac{2 \pi}{5} Z R_{\mathrm{N}}^{2} \bar{n}
$$

is introduced, where $Z$ is the atomic number, and $\bar{n}$ is the electron contact density due to $s$-electrons. Assuming that the change in the nuclear radius upon a $\gamma$ transition is $\Delta R_{\mathrm{N}} \ll R_{\mathrm{N}}$, the corresponding shift in the transition energy is ${ }^{61,62}$

$$
\Delta E_{\gamma} \simeq \frac{4 \pi}{5} Z R_{\mathrm{N}}^{2} \frac{\Delta R_{\mathrm{N}}}{R_{\mathrm{N}}} \bar{n} .
$$

Now, if we consider that $\rho_{\mathrm{N}}$ is unaltered by the surrounding electron density, i.e. that $R_{\mathrm{N}}$ and $\Delta R_{\mathrm{N}}$ depend on $Z$ only, $\Delta E_{\gamma}$ becomes purely dependent on $\bar{n}$, i.e. on the chemical environment of the nucleus. The isomer shift $\delta$ is defined as the relative difference between values of $\Delta E_{\gamma}$ for two distinct chemical environments, such that ${ }^{63}$

$$
\begin{aligned}
\delta & =\frac{c}{E_{\gamma}} \frac{4 \pi}{5} Z R_{\mathrm{N}}^{2} \frac{\Delta R_{\mathrm{N}}}{R_{\mathrm{N}}}\left(\bar{n}_{\mathrm{a}}-\bar{n}_{\mathrm{s}}\right) \\
& =\alpha\left(\bar{n}_{\mathrm{a}}-\bar{n}_{\mathrm{s}}\right)
\end{aligned}
$$

where $\bar{n}_{\mathrm{a}}-\bar{n}_{\mathrm{s}}$ is the relative contact density between the absorber and source isomers used in velocity-scanning experiments, and $\alpha$ is a proportionality factor known as the IS calibration constant. As $\delta$ is a relative quantity, a reference material must be chosen for which $\delta=0 \mathrm{~m} \cdot \mathrm{s}^{-1}$. For the $14.4 \mathrm{keV}$ transition in ${ }^{57} \mathrm{Fe}$ that is usually $\alpha$-Fe (a ferromagnet with body centered cubic structure), and hence $\bar{n}_{\mathrm{s}} \equiv \bar{n}(\alpha-\mathrm{Fe})$. Thus, provided that $\alpha$ is known, isomer shifts may be readily estimated from calculated values of $\bar{n}_{\mathrm{a}}$ and $\bar{n}_{\mathrm{s}}$. Details of the calculation of $\alpha$ are reported in Section IIE.

The calculation of the contact density involves integrating the electron density within a sphere of radius $R_{\mathrm{N}}$, here assumed to be, ${ }^{63}$

$$
R_{\mathrm{N}}=\left(R_{0}+\frac{R_{1}}{A^{2 / 3}}+\frac{R_{2}}{A^{4 / 3}}\right) A^{1 / 3}
$$

with $R_{0}=0.9071 \mathrm{fm}, R_{1}=1.105 \mathrm{fm}$ and $R_{2}=$ $-0.548 \mathrm{fm}$, and $A$ is the atomic mass number. For ${ }^{57} \mathrm{Fe}$ this gives $R_{\mathrm{N}}=3.7685 \mathrm{fm}\left(7.1214 \times 10^{-5} \mathrm{Bohr}\right)$. For the sake of example, let us briefly describe the calculation of the relative contact density in Equation 6. Figure 2 depicts the radial electron density centered on a neutral $\mathrm{Fe}$ impurity located at a tetrahedral interstitial site in a 64$\mathrm{Si}$ atom supercell. The horizontal axis spans the integration limits $3.9223 \times 10^{-7} \mathrm{Bohr} \leq r \leq 7.1214 \times 10^{-5} \mathrm{Bohr}$

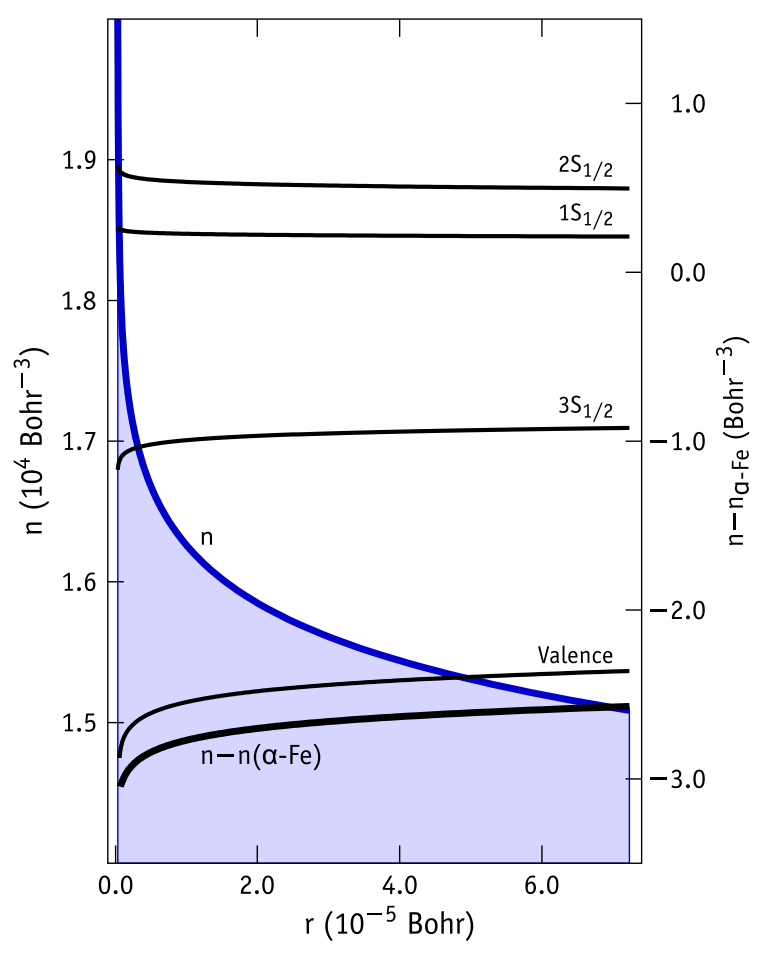

Figure 2. (a) Electron density, $n$, of a neutral $\mathrm{Fe}_{\mathrm{i}}$ impurity in a 64-Si atom supercell (blue curve) as a function of the radial distance from the center of the ${ }^{57} \mathrm{Fe}$ nucleus (with calculated radius $R_{\mathrm{N}}=7.1214 \times 10^{-5} \mathrm{Bohr}$ ). Also shown is the relative density of the neutral $\mathrm{Fe}_{i}$ with respect to the $\alpha$-Fe source, $n-n_{\alpha-\mathrm{Fe}}$. Contributions to the relative density from $N S_{1 / 2}$ core states $(N=1,2$ and 3$)$ and valence states are represented as thinner curves.

used to evaluate all contact densities reported in this paper. The thick curve at the bottom represents the relative density on the $\mathrm{Fe}_{\mathrm{i}}$ impurity with respect to $\alpha$-Fe. These correspond to contact densities $\bar{n}=15985.189 \mathrm{Bohr}^{-3}$ and $\bar{n}(\alpha-\mathrm{Fe})=15987.914 \mathrm{Bohr}^{-3}$, indicating a more diffuse density on the Fe impurity in Si with $\bar{n}-\bar{n}(\alpha-\mathrm{Fe})=$ $-2.725 \mathrm{Bohr}^{-3}$. It is interesting to note that by changing the environment of an Fe atom from metallic $\alpha$-Fe to a tetrahedral interstitial site in $\mathrm{Si}$, most changes in the contact density come from the high-energy states, namely $3 S_{1 / 2}$ and valence.

It is noted that experimental IS values include a second order Doppler contribution as $\delta_{\operatorname{Exp}}=\delta+\delta_{\mathrm{D}}$, which within the harmonic approximation takes the form of $\delta_{\mathrm{D}}=-E / 2 m c$, where $E$ is the time-averaged kinetic energy of the resonant nucleus with oscillating mass $m$ and $c$ is the speed of light in the vacuum. At high temperatures, from the equipartition principle, $E \approx 3 k_{\mathrm{B}} T / 2$ for both absorber and source ( $k_{\mathrm{B}}$ being the Boltzmann constant), and to first order they mutually cancel in Eq. 6. On the other hand, at low temperatures $E$ is approximately the zero-point energy of the resonant atom. We may estimate the impact of neglecting the Doppler contribution to relative IS shifts of $\mathrm{Fe}$ defects in Si by looking at the highest vibrational frequencies in the phonon density of 
states. For the source $(\alpha-\mathrm{Fe})$, the highest allowed phonon frequency is about $\nu=9.3 \mathrm{THz}(\hbar \omega \approx 40 \mathrm{meV}) .{ }^{64} \mathrm{Al}-$ though zero-point motion energies for $\mathrm{Fe}$ defects in $\mathrm{Si}$ are not available, we make use of the highest phonon frequency in $\beta$ - $\mathrm{FeSi}_{2}$, i.e., $\nu=15 \mathrm{THz}(\hbar \omega \approx 62 \mathrm{meV}){ }^{65}$ which is the most stable phase for iron disilicide. Accordingly, for a vibrating ${ }^{57} \mathrm{Fe}$ nucleus in both materials, the difference between Doppler contributions is only about $0.03 \mathrm{~mm} / \mathrm{s}$.

For a state with nuclear spin $I>1 / 2$ the nuclear charge density is aspherical and the expansion of $\phi(\mathbf{r})$ includes a quadrupolar term $\phi_{2}$, usually denoted $Q$, which interacts electrostatically with the local EFG. ${ }^{29}$ The EFG is a traceless tensor, $V_{x x}+V_{y y}+V_{z z}=0$, so, by adopting the convention whereby $\left|V_{x x}\right| \leq\left|V_{y y}\right| \leq\left|V_{z z}\right|$, the asymmetry parameter

$$
\eta=\left(V_{x x}-V_{y y}\right) / V_{z z},
$$

and $V_{z z}$ are sufficient to describe $V$ in the principal axis system. As $I=3 / 2$ for the excited state in the $14.4 \mathrm{keV}$ transition in ${ }^{57} \mathrm{Fe}$, the quadrupolar interaction results in a doublet with separation given by the quadrupole splitting $^{29}$

$$
\Delta=\frac{Q c}{2 E_{\gamma}} V_{z z} \sqrt{1+\frac{\eta^{2}}{3}},
$$

where $V_{z z} \sqrt{1+\eta^{2} / 3}$ is often termed the effective electric field gradient, $V_{\text {eff }}$. The sign of the experimental quadrupole splitting cannot always be determined, although it is possible to do so in some cases, e.g. by further splitting the doublet via a magnetic interaction or by considering the relative intensities of the lines as a function of the orientation of the crystalline sample. ${ }^{66}$ Equation 9 allows us to estimate quadrupole splittings from calculated $V_{\text {eff }}$ values, provided that we know the nuclear quadrupole moment $Q$ for the ${ }^{57} \mathrm{Fe}$ nucleus. Although this has been previously calculated as $Q=0.17 \mathrm{~b}$ (Barn units) from first-principles, ${ }^{67,68}$ we reproduce the calibration procedure in Section II E below.

\section{Formation energy of Fe defects in SiC}

Formation energies of defects were all calculated within the PAW method according to the usual approach, ${ }^{69}$

$$
E_{\mathrm{f}}=E_{\mathrm{def}}-\sum_{i} n_{i} \mu_{i}
$$

where charge neutrality is assumed, and $E_{\text {def }}$ is the total energy of a supercell with $n_{i}$ atoms of species $i$ whose chemical potential $\mu_{i} \equiv \partial G_{\text {std }} / \partial N_{i}$. Here $G_{\text {std }}$ is the Gibbs free energy of an ensemble of atoms in some standard phase containing $N_{i}$ elements. Calculating $\mu_{i}$ is quite straightforward for a defect in a homopolar semiconductor. For instance, in the case of an iron impurity in $\mathrm{Si}, \mu_{\mathrm{Si}}$ is readily calculated from the energy per atom in a pristine $\mathrm{Si}$ unit cell, while $\mu_{\mathrm{Fe}}$ can be estimated from the energy per $\mathrm{Fe}$ atom in $\beta-\mathrm{FeSi}_{2}$ as $\mu_{\mathrm{Fe}}=\left(E_{\beta-\mathrm{FeS} i_{2}}-16 \mu_{\mathrm{Si}}\right) / 8$ where $E_{\beta \text {-FeSi }}$ is the energy per primitive cell of the disilicide comprising $8 \mathrm{FeSi}_{2}$ formula units. The result will effectively give us the formation energy of the Fe impurity in thermodynamic equilibrium with a source/sink of $\mathrm{Fe}$ in the form of $\beta-\mathrm{FeSi}_{2}$.

For a compound semiconductor like $\mathrm{SiC}$ the above formalism becomes more elaborate as $\mu_{\mathrm{Si}}$ and $\mu_{\mathrm{C}}$ can vary within certain limits. For instance, assuming that the standard phases of $\mathrm{Si}$ and $\mathrm{C}$ are crystalline silicon and diamond with respective chemical potentials $\mu_{\mathrm{Si}}^{0}$ and $\mu_{\mathrm{C}}^{0}$, we have $\mu_{\mathrm{Si}} \leq \mu_{\mathrm{Si}}^{0}$ and $\mu_{\mathrm{C}} \leq \mu_{\mathrm{C}}^{0}$, otherwise the $\mathrm{SiC}$ crystal would not be stable and would separate into its elemental phases. On the other hand we have

$$
\mu_{\mathrm{Si}}+\mu_{\mathrm{C}}=\mu_{\mathrm{SiC}}=\mu_{\mathrm{Si}}^{0}+\mu_{\mathrm{C}}^{0}-H_{\mathrm{f}, \mathrm{SiC}},
$$

where $\mu_{\mathrm{SiC}}$ is the energy per formula unit in the $\mathrm{SiC}$ crystal and $H_{\mathrm{f}, \mathrm{SiC}}$ is the heat of formation of SiC. Hence, we can arrive at

$$
\begin{aligned}
\mu_{\mathrm{Si}} & =\left(\mu_{\mathrm{SiC}}+\Delta \mu\right) / 2 \\
\mu_{\mathrm{C}} & =\left(\mu_{\mathrm{SiC}}-\Delta \mu\right) / 2,
\end{aligned}
$$

with $\Delta \mu_{\mathrm{SiC}}^{0}-H_{\mathrm{f}, \mathrm{SiC}} \leq \Delta \mu \leq \Delta \mu_{\mathrm{SiC}}^{0}+H_{\mathrm{f}, \mathrm{SiC}}$ and $\Delta \mu_{\mathrm{SiC}}^{0}=\mu_{\mathrm{Si}}^{0}-\mu_{\mathrm{C}}^{0}$, where the lower and upper limits of $\Delta \mu$ account for a $\mathrm{SiC}$ crystal grown under Si-rich conditions $\left(\Delta \mu=\Delta \mu_{\mathrm{SiC}}^{0}-H_{\mathrm{f}, \mathrm{SiC}}\right)$ or C-rich conditions $\left(\Delta \mu=\Delta \mu_{\mathrm{SiC}}^{0}+H_{\mathrm{f}, \mathrm{SiC}}\right)$. Finally, to obtain $H_{\mathrm{f}, \mathrm{SiC}}$ we simply use Eq. 11 along with values for $\mu_{\mathrm{Si}}^{0}, \mu_{\mathrm{C}}^{0}$ and $\mu_{\mathrm{SiC}}$ calculated from bulk cells with their respective equilibrium lattice parameters. This gives $H_{\mathrm{f}, \mathrm{SiC}}=0.54 \mathrm{eV}$, which compares fairly well with the experimental value of $0.68 \mathrm{eV} .{ }^{70}$

\section{E. Electrical Levels}

Electrical levels were calculated using the marker method. ${ }^{71}$ This approach is based on a comparison between electron affinities $(A)$ or ionization energies $(I)$ of a particular defect under scrutiny, with analogous $A$ 's and $I$ 's calculated for a reference system (referred to as marker). Accordingly, a donor level with respect to the valence band top is then obtained as

$$
\begin{aligned}
E_{\text {def }}(q / q+1)-E_{\mathrm{v}} & =I_{\text {def }}(q / q+1)-I_{\text {mark }}(q / q+1)+ \\
& +\left\{E_{\operatorname{mark}}(q / q+1)-E_{\mathrm{v}}\right\}_{\exp },
\end{aligned}
$$

where the $I$ values are calculated from total energies $E(q)$ for specific charge states, $I(q / q+1)=E(q)-E(q+1)$, for the examined defect $\left(I_{\text {def }}\right)$ and marker $\left(I_{\text {mark }}\right)$, and finally the term between curly brackets is an experimental quantity and refers to the donor level of the marker with respect to $E_{\mathrm{v}}$. Analogously, for acceptor levels we have, 


$$
\begin{aligned}
E_{\mathrm{c}}-E_{\mathrm{def}}(q-1 / q) & =A_{\mathrm{mark}}(q-1 / q)-A_{\mathrm{def}}(q-1 / q)- \\
& -\left\{E_{\mathrm{c}}-E_{\mathrm{mark}}(q-1 / q)\right\}_{\exp },
\end{aligned}
$$

where electron affinities are calculated as $A(q-1 / q)=$ $E(q-1)-E(q)$.

Provided that there is a similarity in the shape and localization between donor (or acceptor) states of the examined defect and marker, this method is claimed to mitigate well known difficulties in the calculation of defect levels through error cancelation. The errors essentially derive from the non-exact treatment of the electronic exchange-correlation, and from finite-size effects due to insufficiently large supercell, like electronic dispersion, elastic strain or long-ranged electrostatic interactions across a lattice of charged defects. ${ }^{72}$ In the calculation of the levels of Fe related defects in $\mathrm{Si}$, we adopted the interstitial Ti impurity as a marker defect. Like most defects scrutinized below, Ti is an interstitial metallic impurity, and has levels measured at $E_{\mathrm{c}}-E(-/ 0)=0.09 \mathrm{eV}$, $E(0 /+)-E_{\mathrm{v}}=0.87 \mathrm{eV}$ and $E(0 /+)-E_{\mathrm{v}}=0.26 \mathrm{eV} \cdot{ }^{73}$ A handicap of the marker method is precisely its dependence on a particular measurement. Since the assignment of the Ti levels was recently questioned, ${ }^{74,75}$ we double checked the results using interstitial and substitutional copper marker levels, namely $\mathrm{Cu}_{\mathrm{i}}(0 /+), \mathrm{Cu}_{\mathrm{s}}(-/ 0)$ and $\mathrm{Cu}_{\mathrm{s}}(=/-)$ at $E_{\mathrm{c}}-0.15 \mathrm{eV}, E_{\mathrm{v}}+0.41 \mathrm{eV}$ and $E_{\mathrm{c}}-0.17 \mathrm{eV}$, respectively. ${ }^{76-78}$ Mössbauer calibration constants

The IS calibration constant $(\alpha)$ and the nuclear quadrupole moment $(Q)$ for the $14.4 \mathrm{keV}$ transition of ${ }^{57} \mathrm{Fe}$ were obtained by fitting experimental values of the IS $\left(\delta_{\operatorname{Exp}}\right)$ and the QS $\left(\Delta_{\operatorname{Exp}}\right)$ to calculated values of $\bar{n}-\bar{n}(\alpha-\mathrm{Fe})$ and $V_{\text {eff }}$, through the respective linear relationships expressed in Eqs. 6 and 9. To this end, we chose a collection of Fe-related compounds that cover a wide range of $\delta_{\operatorname{Exp}}$ and $\Delta_{\operatorname{Exp}}$ values. Since we are interested in the calculation of Mössbauer parameters of $\mathrm{Fe}$ defects in $\mathrm{Si}$, several iron silicides were included in that collection. We found that considering crystalline structures with their respective relaxed (theoretical) lattice constants, resulted in considerable scattering in the linear plots. This is perhaps due to the rather distinct bonding character among the materials considered, which leads to non-systematic errors from the exchange-correlation treatment. Hence, in line with Refs. 67 and 68, crystalline structures with experimental lattice constants were used for the calculation of $\alpha$ and $Q$.

Table II lists all Fe-compounds employed in the calibration procedure. $\alpha$-Fe is the ferromagnetic ground state of iron with body-centered cubic structure (Im $\overline{3} m$ space group). In line with most Mössbauer experiments, this is considered the reference substance in the calculation of IS values. The APW + lo calculation employed a MP- $18^{3}$ grid of special k-points to sample the BZ. The calculated magnetic moment per primitive cell (per Fe atom) was $M=2.18 \mu_{\mathrm{B}}$, where $\mu_{\mathrm{B}}$ is the Bohr magneton. This compares well with the experimental value $M=2.22 \mu_{\mathrm{B}} \cdot{ }^{97}$
TiFe is a metallic compound that crystalizes in the $\mathrm{CsCl}$ prototypical cubic structure ( $P m \overline{3} m$ space group). Although it has two transition metals per primitive cell, it is a diamagnetic compound. The BZ of this crystal was sampled with a MP- $18^{3}$ grid of $\mathbf{k}$-points and the resulting relative contact density was $\bar{n}-\bar{n}(\alpha-\mathrm{Fe})=0.6754 \mathrm{Bohr}^{3}$. This is consistent with some electron transfer from Ti to Fe as already reported in Ref. 98.

The inter-metallic $\mathrm{Fe}_{3} \mathrm{Si}$ solid crystallizes in the $\mathrm{DO}_{3}$ structure $(F \bar{m} 3 m$ space group $)$ and is a ferromagnetic Heusler compound that has attracted much interest. ${ }^{99}$ This structure can be viewed as two inter-penetrating zincblende lattices offsetted along the cube edge by $a / 2$ (where $a$ the lattice constant). ${ }^{83}$ While one of the sublattices comprises two inequivalent $\mathrm{Fe}$ atoms $\left(\mathrm{Fe}_{\mathrm{A}}\right.$ and $\mathrm{Fe}_{\mathrm{B}}$ ), the second sub-lattice is made of a $\mathrm{Fe}_{\mathrm{C}}$ and $\mathrm{Si}$ atom pair. Importantly, $\mathrm{Fe}_{\mathrm{A}}$ and $\mathrm{Fe}_{\mathrm{C}}$ are equivalent by symmetry and $\mathrm{Fe}_{\mathrm{B}}$ sits on a site that is similar to that in $\alpha-\mathrm{Fe}$ - it has 8 equivalent Fe first neighbors at the corners of a cube. The BZ was sampled using a MP$16^{3}$ grid of k-points. Calculated magnetic moments are $M\left(\mathrm{Fe}_{\mathrm{A} / \mathrm{C}}\right)=1.38 \mu_{\mathrm{B}}$ and $M\left(\mathrm{Fe}_{\mathrm{B}}\right)=2.58 \mu_{\mathrm{B}}$. The latter is close to that in $\alpha$-Fe and both compare well the experimental values of $1.35 \mu_{\mathrm{B}}$ and $2.2-2.4 \mu_{\mathrm{B}}$, respectively. ${ }^{100}$

$\alpha-\mathrm{FeSi}_{2}$ is a high-temperature stable $\left(967^{\circ} \mathrm{C} \lesssim T \lesssim\right.$ $1223^{\circ} \mathrm{C}$ ) iron disilicide with tetragonal crystal structure. It is a metallic and diamagnetic compound that is metastable with respect to the structure observed at low-temperatures, namely $\beta-\mathrm{FeSi}_{2}$. The energy difference between fully relaxed $\alpha$ and $\beta$ phases was calculated at $0.18 \mathrm{eV} /$ f.u., comparing well with $0.19 \mathrm{eV} /$ f.u. from previous calculations. ${ }^{60}$ The $\beta$-FeSi 2 phase attracted much attention due to its semiconducting nature with a band gap of $\sim 0.85 \mathrm{eV}$ and envisaged applications in optoelectronics and photovoltaics. ${ }^{101}$ Despite many experimental and theoretical efforts, there is still no agreement about the characteristics and the nature of the band gap in this material. ${ }^{60,102} \beta-\mathrm{FeSi}_{2}$ is a base-centered orthorhombic crystal (space group $\mathrm{Cmca}$ ) with $8 \mathrm{Fe}$ atoms (occupying two inequivalent sites, namely $\mathrm{Fe}_{\mathrm{I}}$ and $\mathrm{Fe}_{\mathrm{II}}$ ) and $16 \mathrm{Si}$ atoms per primitive cell. ${ }^{87}$ Each Fe species is surrounded by a Jahn-Teller distorted cube of Si atoms, and the material is non-magnetic. Among the silicides, the $\beta-\mathrm{FeSi}_{2}$ is the only one where a non-axially symmetric EFG tensor is obtained $(\eta>0)$, namely, $\eta_{\mathrm{I}}=0.62$ and $\eta_{\mathrm{II}}=0.75$, for $\mathrm{Fe}_{\mathrm{I}}$ and $\mathrm{Fe}_{\mathrm{II}}$, respectively. Due to several effects, the $\eta$ parameters could not be measured reliably. However, they are in qualitative agreement with previous linearmuffin-tin orbital (LMTO) calculations $\left(\eta_{\mathrm{I}}=0.36\right.$ and $\left.\eta_{\mathrm{I}}=0.41\right) .{ }^{103}$ Finally, within the Fe-Si phase diagram, we also considered a monosilicide, namely $\epsilon$-FeSi, which is also a non-magnetic semi-metallic material. It crystallizes with a cubic lattice, and contains $4 \mathrm{Fe}(\mathrm{Si})$ atoms per primitive cell at trigonal sites (space group $P 2_{1} 3$ ). ${ }^{89,90,104}$ For the silicides, BZ sampling grids were MP- $16^{2} \times 14$, MP- $6^{3}$ and MP- $12^{3}$ for the $\alpha, \beta$ and $\epsilon$ phases, respectively.

Three iron halides, respectively $\mathrm{FeF}_{2}, \mathrm{FeBr}_{2}$ and 
Table II. Crystal name, space-group, unit cell lattice parameters (in $\AA$ ), lattice site of Fe (when applicable), calculated relative contact densities $(\bar{n}-\bar{n}(\alpha$-Fe $))$, experimental isomer shifts $\left(\delta_{\operatorname{Exp}}\right)$, calculated effective electric field gradients $\left(V_{\text {eff }}\right)$, and experimental quadrupole splittings $\left(\Delta_{\operatorname{Exp}}\right)$ for Fe nuclei in various compounds used to find the Mössbauer calibration constants. The sign of the $\Delta_{\text {Exp }}$ values is shown for the cases where direct measurements are available. $\mathrm{Fe}_{3} \mathrm{Si}$ and $\beta$-FeSi 2 crystals contain two inequivalent $\mathrm{Fe}$ atoms $\left(\mathrm{Fe}_{\mathrm{A}, \mathrm{C}} / \mathrm{Fe}_{\mathrm{B}}\right.$ and $\mathrm{Fe}_{\mathrm{I}} / \mathrm{Fe}_{\mathrm{II}}$, respectively).

\begin{tabular}{|c|c|c|c|c|c|c|c|}
\hline Crystal & Space Group & Unit cell & Site & $\begin{array}{c}\bar{n}-\bar{n}(\alpha-\mathrm{Fe}) \\
\left(\mathrm{Bohr}^{-3}\right)\end{array}$ & $\begin{array}{c}\delta_{\operatorname{Exp}} \\
(\mathrm{mm} / \mathrm{s})\end{array}$ & $\begin{array}{c}V_{\text {eff }} \\
\left(\times 10^{21} \mathrm{~V} / \mathrm{m}^{2}\right)\end{array}$ & $\begin{array}{c}\Delta_{\operatorname{Exp}} \\
(\mathrm{mm} / \mathrm{s})\end{array}$ \\
\hline$\alpha-\mathrm{Fe}$ & Im $\overline{3} m$ & $a=2.8601^{79,80}$ & & 0.0 & 0.0 & & \\
\hline $\mathrm{TiFe}$ & $P m \overline{3} m$ & $a=2.9789^{81}$ & & 0.6754 & $-0.145^{82}$ & & \\
\hline $\mathrm{Fe}_{3} \mathrm{Si}$ & $F m \overline{3} m$ & $a=5.653^{83}$ & $\mathrm{Fe}_{\mathrm{A}, \mathrm{C}}$ & -0.9746 & $+0.26^{84}$ & & \\
\hline$\alpha-\mathrm{FeSi}_{2}$ & $P 4 / m m m$ & $\begin{array}{l}a=2.6955^{85} \\
c=5.1444^{85}\end{array}$ & $\mathrm{Fe}_{\mathrm{B}}$ & $\begin{array}{l}-0.2183 \\
-0.8494\end{array}$ & $\begin{array}{l}+0.08^{84} \\
+0.202^{86}\end{array}$ & -4.0398 & $-0.730^{86}$ \\
\hline$\beta-\mathrm{FeSi}_{2}$ & Cmca & $\begin{array}{l}a=7.791^{87} \\
b=7.883^{87} \\
c=9.863^{87}\end{array}$ & $\begin{array}{l}\mathrm{Fe}_{\mathrm{I}} \\
\mathrm{Fe}_{\mathrm{II}}\end{array}$ & $\begin{array}{l}-0.2972 \\
-0.3642\end{array}$ & $\begin{array}{l}+0.076^{88} \\
+0.091^{88}\end{array}$ & $\begin{array}{l}+2.9768 \\
-1.6932\end{array}$ & $\begin{array}{l}+0.525^{88} \\
-0.315^{88}\end{array}$ \\
\hline$\epsilon-\mathrm{FeSi}$ & $P 2_{1} 3$ & $a=4.489^{89}$ & & -1.0545 & $+0.282^{90}$ & +2.7874 & $+0.495^{90}$ \\
\hline $\mathrm{FeF}_{2}$ & $P 4_{2} / m n m$ & $\begin{array}{l}a=4.6966^{91} \\
c=3.3091^{91}\end{array}$ & & -5.44238 & $+1.467^{92}$ & +15.166 & $+2.85^{92}$ \\
\hline $\mathrm{FeF}_{3}$ & $R \overline{3} c$ & $\begin{array}{l}a=5.362^{93} \\
\alpha=57.94^{93}\end{array}$ & & -1.8808 & $+0.489^{94}$ & +0.2486 & $0.044^{94}$ \\
\hline $\mathrm{FeBr}_{2}$ & $P \overline{3} m 1$ & $\begin{array}{l}a=3.772^{95} \\
c=6.223^{95}\end{array}$ & & -4.3077 & $+1.120^{96}$ & +6.3969 & $1.132^{96}$ \\
\hline
\end{tabular}

$\mathrm{FeF}_{3}$, were also considered in the collection of calibration compounds. They are all anti-ferromagnetic insulators and show a wide spectrum of isomer shifts and quadrupole splittings (in decreasing order as they are referred). $\mathrm{FeF}_{2}$ crystallizes in the rutile structure $\left(P 4_{2} / m n m\right.$ space group), the conventional cell has two formula units where the $\mathrm{Fe}^{2+}$ magnetic moments align anti-parallel along the $c$-axis. Our calculations indicate that within the muffin-tin sphere of $\mathrm{Fe}$, the magnetic moments are $M(\mathrm{Fe})= \pm 3.79 \mu_{\mathrm{B}}$, matching previous PAW calculations, ${ }^{105}$ and not far from the experimental figure $M(\mathrm{Fe})= \pm 3.93 \mu_{\mathrm{B}} \cdot{ }^{106} \mathrm{FeBr}_{2}$ crystallizes with the $\mathrm{CdI}_{2}$ structure $(P \overline{3} m 1$ space group), comprising hexagonal layers of $\mathrm{Fe}$ atoms sandwiched between bromine atom layers. ${ }^{95}$ The magnetic structure of $\mathrm{FeBr}_{2}$ comprises alternate anti-parallel magnetized layers of $\mathrm{Fe}$ atoms, with a large measured magnetization $M(\mathrm{Fe})=$ $\pm 4.4 \mu_{\mathrm{B}}$ per $\mathrm{Fe}^{2+}$ ion. $^{95}$ Our calculations account only for $M(\mathrm{Fe})=3.76 \mu_{\mathrm{B}}$, perhaps resulting from insufficiencies in the semi-local treatment of exchange-correlation interactions in accounting for the van der Waals type bonding between the anti-ferromagnetic $\mathrm{FeBr}_{2}$ layers. Finally, $\mathrm{FeF}_{3}$ is a rhombohedral crystal ( $R \overline{3} c$ space group) and a canted anti-ferromagnet where $\mathrm{Fe}^{3+}$ ions are located at the center of octahedra of six fluorine atoms which are slightly tilted with respect to the crystallographic axes. ${ }^{93,107}$ Among the iron halides, only $\mathrm{FeF}_{2}$ has a non-axial EFG with a calculated asymmetry parameter $\eta=0.32$, in reasonable agreement with the experimental estimate $\eta=0.4 .^{92}$ For the iron halides, BZ sampling grids were $\mathrm{MP}-12^{2} \times 16, \mathrm{MP}-12^{2} \times 4$ and $\mathrm{MP}-12^{3}$ for $\mathrm{FeF}_{2}$, $\mathrm{FeBr}_{2}$ and $\mathrm{FeF}_{3}$, respectively.

In Figure 3 we show two plots based on the data from Table II, representing experimental isomer shifts

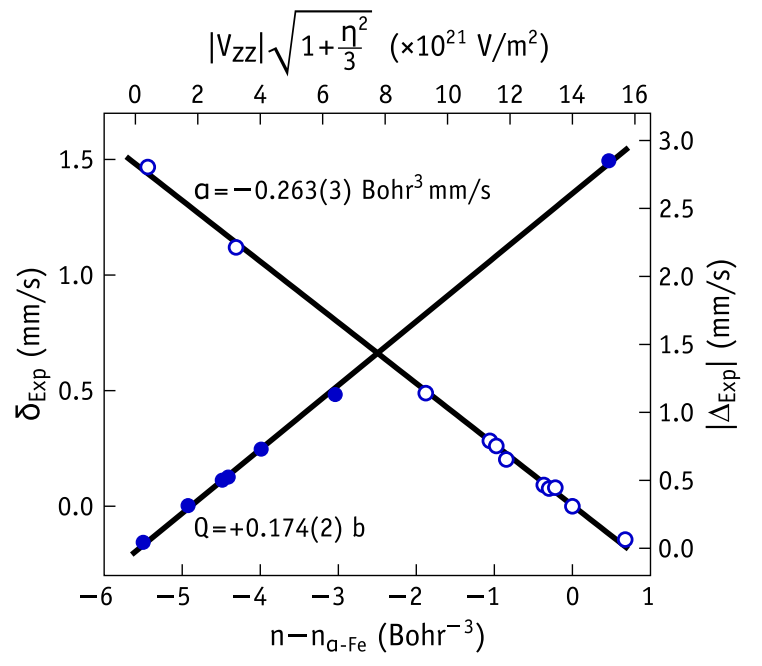

Figure 3. Fit of the isomer shift calibration constant $(\alpha)$ and ${ }^{57} \mathrm{Fe}$ nuclear quadrupole moment $(Q)$ using data from Table II. Open symbols represent experimental isomer shifts $\left(\delta_{\operatorname{Exp}}\right)$ against the calculated relative contact densities, $\bar{n}-$ $\bar{n}(\alpha-\mathrm{Fe})$. Closed symbols represent absolute experimental quadrupole splittings, $\left|\Delta_{\text {Exp }}\right|$, plotted against the absolute effective electric field gradients, $\left|V_{z z}\right|\left(1+\eta^{2} / 3\right)^{1 / 2}$. Errors quoted within parentheses derive from the least squares linear regression. Total errors in $\alpha$ and $Q$ are expected to be $5-10 \%$.

versus calculated relative contact densities (open symbols) and experimental quadrupole splittings versus calculated effective EFG's (closed symbols) for the materials described above. Least squares linear fits to the data resulted in an IS calibration constant $\alpha=$ 
$-0.26 \mathrm{Bohr}^{3} \mathrm{~mm} / \mathrm{s}$ and in a nuclear quadrupole moment $Q=+0.17 \mathrm{~b}$. The positive sign of the nuclear quadrupole moment is deduced from the sign of $\Delta_{\exp }$ for the silicides and $\mathrm{FeF}_{2}$. The calculated values for $\alpha$ and $Q$ are in good agreement with previous full-potential APW calculations, namely those by Wdowik and Ruebenbauer ${ }^{68}$ where $\alpha=-0.29 \mathrm{Bohr}^{3} \mathrm{~mm} / \mathrm{s}$ and $Q=+0.17 \mathrm{~b}$ and those by Dufek et al. ${ }^{67}$ where $Q=+0.16$ b was obtained.

\section{IRON DEFECTS IN SILICON}

\section{A. Solubility and lattice location of dissolved iron in silicon}

In iron-plated samples annealed at high temperatures, the solubility of in-diffused Fe in the Si bulk depends on the formation of an equilibrium silicide/Si interface underneath the surface. ${ }^{108}$ Below the Si-Fe eutectic $(T \lesssim$ $1480 \mathrm{~K}$ ), the maximum concentration of all iron dissolved in the bulk, $\left[\mathrm{Fe}_{\mathrm{Si}}\right]$, and that in the silicide phase, $\left[\mathrm{Fe}_{\mathrm{FeSi}}\right]$, are related as follows

$$
\ln \left(\left[\mathrm{Fe}_{\mathrm{Si}}\right] /\left[\mathrm{Fe}_{\mathrm{FeSi}}\right]\right)=\Delta S / k_{\mathrm{B}}-\Delta H / k_{\mathrm{B}} T,
$$

where $\Delta S$ and $\Delta H$ are the excess relative partial entropy and enthalpy of formation, respectively, resulting from the transferral of an $\mathrm{Fe}$ atom from the silicide to bulk Si. Assuming that $\left[\mathrm{Fe}_{\mathrm{FeSi}}\right]$ is temperature independent, for elemental impurities like tetrahedral interstitial and substitutional iron, Eq. 16 becomes an Arrhenius relation,

$$
\left[\mathrm{Fe}_{\mathrm{Si}}\right]=c_{0} \exp \left(\Delta S / k_{\mathrm{B}}-\Delta H / k_{\mathrm{B}} T\right),
$$

where $c_{0}$ is the number of possible defect sites and orientations per unit volume in the crystal (for tetrahedral interstitial and substitutional impurities in $\mathrm{Si}$ we have $\left.c_{0}=5 \times 10^{22} \mathrm{~cm}^{-3}\right)$. Using measured values of entropy $\left(\Delta S / k_{\mathrm{B}}=8.2\right)$ and enthalpy of formation for dissolved $\mathrm{Fe}$ in $\mathrm{Si},{ }^{108}$ one obtains a solubility $[\mathrm{Fe}] \approx 4.7 \times 10^{15} \mathrm{~cm}^{-3}$ at $T=1100^{\circ} \mathrm{C}$. While the change in entropy is a quantity that is difficult to estimate, we can easily calculate the formation enthalpy of $\mathrm{Fe}_{\mathrm{i}}$ and $\mathrm{Fe}_{\mathrm{s}}$ defects by using appropriate chemical potentials for Fe and Si species. Assuming that the source of $\mathrm{Fe}$ is the most stable phase of iron disilicide, namely $\beta-\mathrm{FeSi}_{2}$ (see Sec. IID), we have $\Delta H\left(\mathrm{Fe}_{\mathrm{i}}\right)=E_{\mathrm{def}}\left(\mathrm{Fe}_{\mathrm{i}}\right)-216 \mu_{\mathrm{Si}}-\mu_{\mathrm{Fe}}=2.73 \mathrm{eV}$ and $\Delta H\left(\mathrm{Fe}_{\mathrm{s}}\right)=E_{\text {def }}\left(\mathrm{Fe}_{\mathrm{s}}\right)-215 \mu_{\mathrm{Si}}-\mu_{\mathrm{Fe}}=3.23 \mathrm{eV}$. These calculations were carried out using 216-Si atom supercells with respective defects and a $\beta$ - $\mathrm{FeSi}_{2}$ primitive cell (using MP- $2^{3}$ and MP- $6^{3}$ special k-point sets, respectively). We note that the close agreement between $\Delta H\left(\mathrm{Fe}_{\mathrm{i}}\right)$ and the experimental figure from EPR data $(\Delta H=2.87 \mathrm{eV})$ suggests that the iron source in high-temperature in-diffused samples is actually a $\beta-\mathrm{FeSi}_{2}$ layer. In fact, considering $\mu_{\mathrm{Fe}}$ from $\alpha-\mathrm{FeSi}_{2}$ or $\mathrm{Fe}_{3} \mathrm{Si}$ phases, the agreement between calculated and experimental formation enthalpies worsens considerably, with $\Delta H\left(\mathrm{Fe}_{\mathrm{i}}\right)=2.55 \mathrm{eV}$ and $1.80 \mathrm{eV}$, respectively.

Assuming that formation entropy values of $\mathrm{Fe}_{\mathrm{i}}$ and $\mathrm{Fe}_{\mathrm{S}}$ (with respect to $\mathrm{Fe}$ in $\beta-\mathrm{FeSi}_{2}$ ) are dominated by configurational contributions, ${ }^{25}$ they should be comparable. Hence, from $\left[\mathrm{Fe}_{\mathrm{s}}\right] /\left[\mathrm{Fe}_{\mathrm{i}}\right]=$ $\exp \left[\left(-\Delta H\left(\mathrm{Fe}_{\mathrm{s}}\right)+\Delta H\left(\mathrm{Fe}_{\mathrm{i}}\right)\right) / k_{\mathrm{B}} T\right]$, and for $T \sim 900^{\circ} \mathrm{C}$ $1200^{\circ} \mathrm{C}$ we obtain a concentration of $\mathrm{Fe}_{\mathrm{s}}$ which is about 1\%-2\% of the total dissolved Fe. In Ref. 27 the authors reported that within the above temperature interval, the concentration of $\mathrm{Fe}_{\mathrm{i}}$ (detected by EPR) was slightly but invariably lower than the total $\mathrm{Fe}$ in the samples (from NAA). Since some of the iron could have precipitated during the quenching stage, it was suggested that this imbalance represented an upper limit for $\left[\mathrm{Fe}_{\mathrm{s}}\right]$.

It is also interesting to note that Gilles and his coworkers ${ }^{19}$ reported the enhancement of the Fe solubility in $\mathrm{n}^{+}$-type $\mathrm{Si}$ by up to four orders of magnitude in the temperature range $700^{\circ} \mathrm{C}-850^{\circ} \mathrm{C}$. This was attributed to the formation of immobile substitutional Fe and possibly to pairing with phosphorous. Also from emission channeling in n-type $\mathrm{Si}$, the concentration of substitutional Fe along with that of a defect referred to as near bond-centered iron, was found to be larger than that of $\mathrm{Fe}_{\mathrm{i}}$, while the opposite was observed in $\mathrm{p}^{+}$-doped samples, i.e. $\mathrm{Fe}_{\mathrm{i}}$ was the most abundant impurity. ${ }^{11}$ The small difference between the formation enthalpies of $\mathrm{Fe}_{\mathrm{i}}$ and $\mathrm{Fe}_{\mathrm{s}}$, combined with previous predictions that $\mathrm{Fe}_{\mathrm{s}}$ is a deep acceptor, ${ }^{25}$ could explain the measurements referred above. Nevertheless, there is a clear need for further experimental and theoretical efforts in order to identify $\mathrm{Fe}_{\mathrm{s}}$ and its electronic levels .

\section{B. Interstitial iron in silicon}

From PAW calculations, we arrived at the following ground states for Fe interstitial in silicon, ${ }^{1} \mathrm{Fe}_{\mathrm{i}}^{0}\left(T_{d}\right)$, ${ }^{3 / 2} \mathrm{Fe}_{\mathrm{i}}^{+}\left(C_{2 v}\right)$ and ${ }^{2} \mathrm{Fe}_{\mathrm{i}}^{++}\left(T_{d}\right)$, where the total spin/charge is left/right-superscripted to the Fe symbol and the symmetry of the defect is specified within parentheses. In the neutral charge state the nearest neighboring Fe-Si distance is $2.404 \AA$ (only $0.036 \AA$ longer than the bulk Si-Si bond length). The same Fe-Si distance increases by less than $0.01 \AA$ for each electron that is ionized from the center. The orthorhombic distortion obtained for ${ }^{3 / 2} \mathrm{Fe}_{\mathrm{i}}^{+}$is rather small and relates to a displacement of the Fe atom along the $\langle 100\rangle$ direction by $0.06 \AA$, which corresponds to a decrease in the energy of only $50 \mathrm{meV}$ with respect to the $T_{d}$ structure. The spin- 1 and spin- $3 / 2$ states obtained for $\mathrm{Fe}_{i}^{0}$ and $\mathrm{Fe}_{\mathrm{i}}^{+}$correspond to those observed by $\mathrm{EPR},{ }^{5,6,109}$ and agree with previous calculations. ${ }^{110,111}$ Regarding $\mathrm{Fe}_{\mathrm{i}}^{++}$, we will discuss its potential occurrence in a spin-2 state in $\mathrm{p}^{+}$-type material. In this charge state the spin- 1 and spin-0 configurations are unstable - from spin-constrained calculations we found them to be $90 \mathrm{meV}$ and $0.54 \mathrm{eV}$ higher in energy than ${ }^{2} \mathrm{Fe}_{\mathrm{i}}^{++}$. 

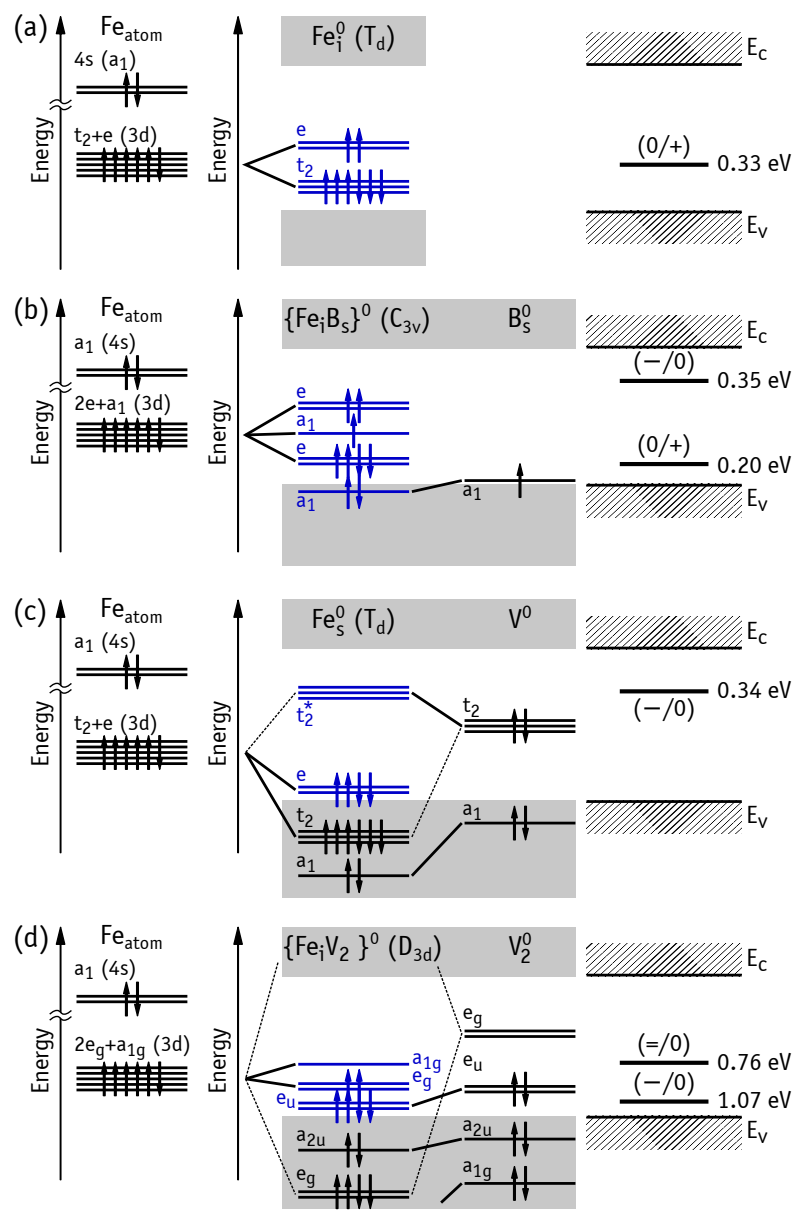

Figure 4. Electronic structure of (a) Interstitial iron, $\mathrm{Fe}_{\mathrm{i}}$, (b) iron-boron pair, $\mathrm{Fe}_{\mathrm{i}} \mathrm{B}_{\mathrm{s}}$, (c) substitutional iron, $\mathrm{Fe}_{\mathrm{s}}$, and (d) iron-divacancy, $\mathrm{Fe}_{\mathrm{i}} \mathrm{V}_{2}$ defects in Si. Diagrams in the middle depict the electronic coupling between atomic iron (left diagrams) and specific defects in $\mathrm{Si}$ (boron, vacancy and divacancy). Diagrams on the right show the calculated electronic levels for each case, where donor and acceptor energies are given with respect to the valence band top and conduction band bottom, respectively. In all diagrams, electronic levels are labelled according to the the point group of the defect under scrutiny. Occupied spin-up/-down states are shown as upward/downward arrows, respectively.

From inspection of the Kohn-Sham band structure we confirm the established model for the electronics of $\mathrm{Fe}_{i}$ in $\mathrm{Si}$. The result is depicted in Figure 4(a) and closely follows the model early proposed by Ludwig and Woodbury. ${ }^{112}$ Before we proceed with the discussion, we note that the departure from $T_{d}$ symmetry in $\mathrm{Fe}_{i}^{+}$is in the present context considered small enough to justify a tetrahedral representation of its electronic states. Basically all $3 \mathrm{~d}$ levels of atomic Fe (in the figure labeled within the $T_{d}$ point group symmetry as $t_{2}+e$ ) are found inside the band gap of $\mathrm{Si}$ which, due to the tetrahedral crystal field, are split into $t_{2}$ (low energy) and $e$ (high energy) states, respectively. Importantly, the neutral Fe impurity adopts a non-oxidized $3 \mathrm{~d}^{8} 4 \mathrm{~s}^{0}$ configuration (un-
Table III. Calculated isomer shifts, $\delta(\mathrm{mm} / \mathrm{s})$ and quadrupole splittings $\Delta(\mathrm{mm} / \mathrm{s})$ for the defects under investigation in several charge states of interest.

\begin{tabular}{ccc}
\hline & $\delta$ & $\Delta$ \\
\hline $\mathrm{Fe}_{\mathrm{i}}(0,+)$ & $0.72,0.67$ & \\
$\mathrm{FeB}_{\mathrm{s}}(-, 0,+)$ & $0.71,0.68,0.64$ & $-0.04,0.57,0.96$ \\
$\mathrm{Fe}_{\mathrm{s}}(-, 0,+)$ & $-0.11,-0.13,-0.14$ & \\
$\mathrm{FeV}_{2}(-, 0)$ & $0.35,0.39$ & $0.40,1.10$ \\
\hline
\end{tabular}

like atomic iron which is $\left.3 \mathrm{~d}^{6} 4 \mathrm{~s}^{2}\right)$. Also in line with the EPR data we found that the ionization of the defect involves a change in the occupation of the triplet (not in the higher energy doublet). Due to exchange interactions, electrons occupying the $e$ state are tightly bound. This results in the formation of a $t_{2}^{4 \uparrow}+e^{\uparrow \uparrow}$ manifold with net spin $S=3 / 2$. In fact, the most stable ${ }^{1 / 2} \mathrm{Fe}^{+}$state was not $t_{2}^{6}+e^{\uparrow}$, but $t_{2}^{4 \downarrow}+e^{\uparrow \uparrow}$ which was $0.31 \mathrm{eV}$ above the spin- $3 / 2$ ground state. The weak $C_{2 v}$ distortion obtained for $\mathrm{Fe}_{i}^{+}$suggests a possible Jahn-Teller instability driven by the incomplete filling of the triplet state. Experimental evidence for this effect may be inferred from a dynamic broadening of the EPR signal of $\mathrm{Fe}_{i}^{+}$relative to that of $\mathrm{Fe}_{\mathrm{i}}^{0}{ }^{110}$ However, we note that the calculation of Jahn-Teller symmetry breaking using methods based on the Born-Oppenheimer approximation (as presented here), should be considered with care - any quantitative treatment of this effect must account for the electronphonon coupling. By comparing first ionization energies of $\mathrm{Fe}$ and $\mathrm{Ti}$ impurities in 216-atom supercells we arrive at a $\mathrm{Fe}_{\mathrm{i}}(0 /+)$ transition at $E_{\mathrm{v}}+0.33 \mathrm{eV}$ [obtained from $I_{\mathrm{Fe}}(0 /+)-I_{\mathrm{Ti}}(0 /+)=-0.54 \mathrm{eV}$. This compares fairly well with the experimental figure of $E_{\mathrm{v}}+0.38 \mathrm{eV}$ (see for instance Refs. 8 and 9). Similarly, by comparison with $E_{\mathrm{c}}-\mathrm{Cu}_{\mathrm{i}}(0 /+)=0.15 \mathrm{eV}$, the level of $\mathrm{Fe}_{\mathrm{i}}(0 /+)$ is very close to the Ti-marked result and it is calculated at $E_{\mathrm{v}}+0.32 \mathrm{eV}$. Since the $\mathrm{Cu}_{\mathrm{i}}(0 /+)$ marker is referred with respect to the conduction band minimum, a band gap width of $1.17 \mathrm{eV}$ was considered in order to calculate $\mathrm{Fe}_{\mathrm{i}}(0 /+)$ with respect to $E_{\mathrm{v}}$.

Further ionization of the defect also involved electron depletion of the $t_{2}$ triplet state. By comparing $I_{\mathrm{Fe}}(+/+$ $+)$ and $I_{\mathrm{Ti}}(+/++)$ energies we were lead to a second donor level for Fe at $E_{\mathrm{v}}+0.08 \mathrm{eV}$. It is noted that there is no experimental evidence for such a level. This result may suffer from an overestimation of the stability of the high-spin ${ }^{2} \mathrm{Fe}_{\mathrm{i}}^{++}$ground state by the use of a semi-local treatment of the exchange-correlation potential. As a matter of fact, if we consider the energy of the ${ }^{1} \mathrm{Fe}_{i}^{++}$ state, the $\mathrm{Fe}_{\mathrm{i}}(+/++)$ level becomes resonant with the valence band.

In Table III we find the calculated isomer shifts and quadrupole splittings for the defects under investigation in their relevant charge states. From the APW+lo calculations for ${ }^{1} \mathrm{Fe}_{\mathrm{i}}^{0}$ we obtained a relative contact density $\bar{n}\left({ }^{1} \mathrm{Fe}_{\mathrm{i}}^{0}\right)-\bar{n}(\alpha-\mathrm{Fe})=-2.725 \mathrm{Bohr}^{-3}$, and using Eq. 6 we arrive at an isomer shift $\delta\left({ }^{1} \mathrm{Fe}_{\mathrm{i}}^{0}\right)=0.72 \mathrm{~mm} / \mathrm{s}$. Ionization of the $\mathrm{Fe}_{i}$ impurity results in a small increase 
in the (absolute) contact density that corresponds to an isomer shift of $0.67 \mathrm{~mm} / \mathrm{s}$ for ${ }^{3 / 2} \mathrm{Fe}_{i}^{+}$. These results agree reasonably well with the experimental data obtained by the ISOLDE consortium, i.e. $0.77 \mathrm{~mm} / \mathrm{s}$ and $0.72 \mathrm{~mm} / \mathrm{s}$ observed in n-type and p-type $\mathrm{Si}$ and assigned to $\mathrm{Fe}_{i}^{0}$ and $\mathrm{Fe}_{i}^{+}$, respectively. ${ }^{42}$ Extensive measurements in $\mathrm{n}$ - and p-type samples, where ${ }^{57} \mathrm{Fe}$ was introduced by several methods, were also carried out by Yoshida and his group. ${ }^{13,26,43}$ Although their data for p-type Si seems to be in line with other reported data $(\delta=0.8 \mathrm{~mm} / \mathrm{s})$, for $\mathrm{n}$-type material a resonance at $\delta=0.40 \mathrm{~mm} / \mathrm{s}$ has been assigned to $\mathrm{Fe}_{\mathrm{i}}^{0}$. Since our calculations conflict with this assignment, we investigated several possible sources of error, including (i) increasing the BZ sampling grid to MP- $4^{3}$, (ii) bringing the 3 s state of Fe into the valence to be treated within the KohnSham scheme, (iii) including an on-site correction to the exchange-correlation energy by means of the GGA $+U+J$ approach as proposed by Liechtenstein et al. ${ }^{113}$ (with Hubbard and Hund parameters in the range $U=2-5 \mathrm{eV}$ and $J=0-1 \mathrm{eV}$ ), and (iv) using the local density approximation to the electronic exchange-correlation interactions. All these tests resulted in a small and negative charge-induced shift $\delta(+/ 0)=-0.04(2) \mathrm{mm} / \mathrm{s}$, where $\delta(+/ 0) \equiv \delta\left({ }^{3 / 2} \mathrm{Fe}_{\mathrm{i}}^{+}\right)-\delta\left({ }^{1} \mathrm{Fe}_{\mathrm{i}}^{0}\right)$, which is effectively identical to that obtained from $\delta$ values reported in Table III.

The small calculated change in the isomer shift upon ionization of $\mathrm{Fe}_{\mathrm{i}}$ in $\mathrm{Si}$ is also in agreement with previous theoretical reports. Early work by KatayamaYoshida and Zunger ${ }^{114}$ by means of a self-consistent spinpolarized Green's-function method reported $\delta(+/ 0)=$ $-0.06 \mathrm{~mm} / \mathrm{s}$, and more recently Kübler and co-workers ${ }^{41}$ obtained $\delta(+/ 0)=-0.08 \mathrm{~mm} / \mathrm{s}$. Figure 5 depicts the difference between the electron density around the ${ }^{57} \mathrm{Fe}$ nucleus in $\mathrm{Fe}_{i}^{+}$and $\mathrm{Fe}_{\mathrm{i}}^{0}$ defects, represented as $n^{+}(r)-n^{0}(r)$. It also includes partial contributions from S-states (where the relativistic notation is used) and valence. Two main effects dictate the almost identical contact densities in $\mathrm{Fe}_{i}^{+}$and $\mathrm{Fe}_{i}^{0}$, namely (i) the fact that the 4s state is not involved in the ionization process - only $3 \mathrm{~d}$ states (which are nodal at the nucleus) change occupancy, and (ii) a considerable screening of the Fe impurity by the host crystal, meaning that removal of one electron from the triplet state results in a charge flow (electronic relaxation) from ligand atoms towards the Fe site. This is demonstrated by the large positive contribution from the valence to $n^{+}-n^{0}$. Contributions from $2 S_{1 / 2}$ and $3 S_{1 / 2}$ states have similar magnitudes and mutually cancel.

\section{Iron-boron pair in $\mathrm{Si}$}

Our calculations indicate that the pairing of $\mathrm{Fe}$ with substitutional B results in trigonal $\left(C_{3 v}\right)$ complexes with ${ }^{2}\left\{\mathrm{Fe}_{\mathrm{i}} \mathrm{B}_{\mathrm{s}}\right\}^{+},{ }^{3 / 2}\left\{\mathrm{Fe}_{\mathrm{i}} \mathrm{B}_{\mathrm{s}}\right\}^{0}$ and ${ }^{1}\left\{\mathrm{Fe}_{\mathrm{i}} \mathrm{B}_{\mathrm{s}}\right\}^{-}$ground states. Low-spin ${ }^{1}\left\{\mathrm{Fe}_{\mathrm{i}} \mathrm{B}_{\mathrm{s}}\right\}^{+}$and ${ }^{0}\left\{\mathrm{Fe}_{\mathrm{i}} \mathrm{B}_{\mathrm{s}}\right\}^{+}$configurations were $0.06 \mathrm{eV}$ and $0.47 \mathrm{eV}$ above the ground state. From the point of view of its formation, it is instructive to

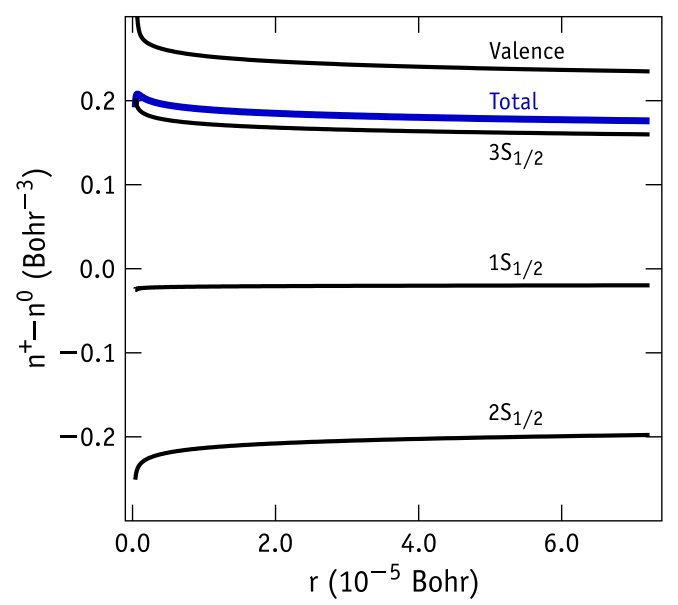

Figure 5. Change in the electron density upon ionization of $\mathrm{Fe}_{\mathrm{i}}$ in $\mathrm{Si}, n^{+}-n^{0}$, as a function of the radial distance from the center of the Fe nucleus. The graph depicts the total change in the density (thick blue curve), along with partial contributions to $n^{+}-n^{0}$ from $N S_{1 / 2}$ core states (up to $N=3$ ) and valence states (thinner black curves).

look at the neutral state as a Coulomb stabilized complex made of ${ }^{3 / 2} \mathrm{Fe}_{\mathrm{i}}{ }^{+}$next to $\mathrm{B}_{\mathrm{s}}^{-}$. Alternatively, we may think of it as a result of electron transfer from the high-energy d-state of $\mathrm{Fe}_{\mathrm{i}}$ to the low-energy acceptor state of boron, meaning that the electronic structure of $\left\{\mathrm{Fe}_{\mathrm{i}} \mathrm{B}_{\mathrm{s}}\right\}^{q}$ resembles that of $\mathrm{Fe}_{\mathrm{i}}^{q+1}$ (perturbed by a $\mathrm{B}_{\mathrm{s}}^{-}$anion). ${ }^{14,115}$ According to Zhao et al. ${ }^{115}$ the effect of a negatively charged $\mathrm{B}_{\mathrm{s}}^{-}$next to $\mathrm{Fe}_{\mathrm{i}}$ is to raise the energy of the $\mathrm{Fe}_{i}$ levels due to Coulomb repulsion. The magnitude of this interaction has been estimated from the measured $\mathrm{Fe}_{\mathrm{i}} \mathrm{B}_{\mathrm{s}}$ and $\mathrm{Fe}_{\mathrm{i}}$ levels ${ }^{8,116}$ as $\mathrm{Fe}_{\mathrm{i}} \mathrm{B}_{\mathrm{s}}(-/ 0)-\mathrm{Fe}_{\mathrm{i}}(0 /+)=\left(E_{\mathrm{c}}-0.26\right)-\left(E_{\mathrm{v}}+0.38\right)=$ $0.53 \mathrm{eV}$, where the band gap of $\mathrm{Si}$ at $T=0 \mathrm{~K}$ is considered to be $E_{\mathrm{c}}-E_{\mathrm{v}}=1.17 \mathrm{eV}$. From here, and hypothesizing that the $\mathrm{Fe}_{\mathrm{i}} \mathrm{B}_{\mathrm{s}}(0 /+)$ level also originates from a Coulomb-raised $\mathrm{Fe}_{\mathrm{i}}(+/++)$ transition resonant with the Si valence band, we readily arrive at an estimate for its location as $\mathrm{Fe}_{\mathrm{i}}(+/++)=\mathrm{FeB}_{\mathrm{s}}(0 /+)-0.53=E_{\mathrm{v}}-0.42 \mathrm{eV}$, where again we made use of the measured donor level of $\mathrm{Fe}_{\mathrm{i}} \mathrm{B}_{\mathrm{s}}$ at $E_{\mathrm{v}}+0.11 \mathrm{eV} \cdot{ }^{76}$ Obviously this analysis is based on the premise that the strength of the interaction between $\mathrm{B}_{\mathrm{s}}^{-}$and the two levels of $\mathrm{Fe}_{\mathrm{i}}$ is the same, which although reasonable, is yet to be demonstrated.

The calculated electronic structure of neutral $\mathrm{Fe}_{\mathrm{i}} \mathrm{B}_{\mathrm{s}}$ is depicted in Figure 4(b). Analogously to $\mathrm{Fe}_{\mathrm{i}}$, we found that the ionization/electron trapping of/by $\mathrm{Fe}_{\mathrm{i}} \mathrm{B}_{\mathrm{s}}$ essentially involves a change in the occupation of a $a_{1}+e$ manifold (once a $t_{2}$ triplet localized on $\mathrm{Fe}_{\mathrm{i}}$ ) below a $e^{\uparrow \uparrow}$ spin-1 doublet. The calculated electronic levels of $\mathrm{Fe}_{\mathrm{i}} \mathrm{B}_{\mathrm{S}}$ marked with Ti are located at $\mathrm{Fe}_{\mathrm{i}} \mathrm{B}_{\mathrm{s}}(0 /+)=E_{\mathrm{v}}+0.20 \mathrm{eV}$ and $\mathrm{Fe}_{\mathrm{i}} \mathrm{B}_{\mathrm{s}}(-/ 0)=E_{\mathrm{c}}-0.35 \mathrm{eV}$, in fair agreement with the corresponding experimental levels measured at $E_{\mathrm{v}}+0.11 \mathrm{eV}$ and $E_{\mathrm{c}}-0.26 \mathrm{eV}$, respectively. ${ }^{117}$ Analogous calculations using $\mathrm{Cu}_{\mathrm{i}}(0 /+)$ and $\mathrm{Cu}_{\mathrm{s}}(-/ 0)$ markers gave $\mathrm{Fe}_{\mathrm{i}} \mathrm{B}_{\mathrm{s}}(0 /+)=E_{\mathrm{v}}+0.19 \mathrm{eV}$ and $\mathrm{Fe}_{\mathrm{i}} \mathrm{B}_{\mathrm{s}}(-/ 0)=$ 
$E_{\mathrm{c}}-0.48 \mathrm{eV}$. The latter figure is edging the usual error bar of the marker method, perhaps because a substitutional marker is not the best choice to compare with an interstitial defect. The fact that we place the $\mathrm{Fe}_{\mathrm{i}} \mathrm{B}_{\mathrm{S}}(0 /+)$ level about $0.1 \mathrm{eV}$ above the measurements suggests that the calculated $\mathrm{Fe}_{\mathrm{i}}(+/++)$ transition reported above at $E_{\mathrm{c}}+0.08 \mathrm{eV}$ is spurious.

Likewise, for the electronic structure, the calculated isomer shifts for $\left\{\mathrm{Fe}_{\mathrm{i}} \mathrm{B}_{\mathrm{s}}\right\}^{q}$ are very similar to those for $\mathrm{Fe}_{\mathrm{i}}^{q+1}$. The results are shown in Table III, where calculated $\delta$ values of $0.71 \mathrm{~mm} / \mathrm{s}$ and $0.68 \mathrm{~mm} / \mathrm{s}$ for $\left\{\mathrm{FeB}_{\mathrm{s}}\right\}^{-}$ and $\left\{\mathrm{FeB}_{\mathrm{s}}\right\}^{0}$ are very close to $0.72 \mathrm{~mm} / \mathrm{s}$ and $0.67 \mathrm{~mm} / \mathrm{s}$ measured for $\mathrm{Fe}_{\mathrm{i}}^{0}$ and $\mathrm{Fe}_{\mathrm{i}}^{+}$, respectively. The fact that we are now dealing with a trigonal center implies the existence of a non-zero EFG at the Fe nucleus and a quadrupole splitting in the Mössbauer signal. The calculations (also reported in Table III) indicate splittings of $\Delta=-0.04 \mathrm{~mm} / \mathrm{s}, 0.57 \mathrm{~mm} / \mathrm{s}$ and $0.96 \mathrm{~mm} / \mathrm{s}$ for $\left\{\mathrm{FeB}_{\mathrm{s}}\right\}^{-}$and $\left\{\mathrm{FeB}_{\mathrm{s}}\right\}^{0}$ and $\left\{\mathrm{FeB}_{\mathrm{s}}\right\}^{+}$. These results indicate that the nuclei of $\mathrm{Fe}$ ions in neutral $\left\{\mathrm{Fe}^{+} \mathrm{B}_{\mathrm{s}}^{-}\right\}$ and positively charged $\left\{\mathrm{Fe}^{++} \mathrm{B}_{\mathrm{s}}^{-}\right\}$complexes experience much larger EFGs than neutral $\mathrm{Fe}$ in negatively charged $\left\{\mathrm{Fe}^{0} \mathrm{~B}_{\mathrm{s}}^{-}\right\}$, where there is no Coulomb attraction between the impurity pair. These results differ considerably from Mössbauer data acquired at $T \approx 900 \mathrm{~K}$ where a signal with a centroid velocity $\delta=0.93 \mathrm{~mm} / \mathrm{s}$ and line splitting $\Delta=1.6 \mathrm{~mm} / \mathrm{s}$ was connected to the $\mathrm{Fe}_{\mathrm{i}} \mathrm{B}_{\mathrm{s}}$ pair (presumably in the neutral charge state). ${ }^{118}$ They are also at variance with a recent proposal that the $\mathrm{Fe}_{\mathrm{i}} \mathrm{B}_{\mathrm{s}}$ pair gives rise to a single resonant line (presumably without or with unresolvable quadrupole splitting) at $\delta=0.42 \mathrm{~mm} / \mathrm{s}^{43}$ On the other hand, they are in much better agreement with earlier work by Bergholz on ${ }^{57} \mathrm{Co}$-contaminated ptype Si, where at least three doublets were observed with intensities that depended on the temperature of the measurements, and were all assigned to ${ }^{57} \mathrm{Co}_{\mathrm{i}} \mathrm{B}_{\mathrm{s}}$ pairs. All these doublets had $\delta$ values of about $0.7 \mathrm{~mm} / \mathrm{s}$, and were split by either $0.21,0.54$ and $1.04 \mathrm{~mm} / \mathrm{s}$, the one with larger $\Delta$ being assigned to the $\langle 111\rangle$-oriented structure studied here. ${ }^{119}$ Such mixed agreement calls for further theoretical analysis and experiments.

\section{Substitutional iron in silicon}

Substitutional Fe was studied in the neutral and negative charge states. We obtained ground state configurations ${ }^{0} \mathrm{Fe}_{\mathrm{s}}^{0}\left(T_{d}\right)$ and ${ }^{1 / 2} \mathrm{Fe}_{\mathrm{s}}^{-}\left(C_{2 v}\right)$. The tetrahedral structure had $2.255 \AA \mathrm{Fe}-\mathrm{Si}$ bonds, while the Fe atom in the $C_{2 v}$ structure was displaced from the perfect lattice by $0.11 \AA$ along $\langle 001\rangle$, resulting in Fe-Si bonds either $2.249 \AA$ or $2.239 \AA$ long. These are somewhat shorter than Si-Si bonds in bulk $\mathrm{Si}(2.368 \AA)$ and also shorter than Fe-Si bonds in $\beta-\mathrm{FeSi}_{2}(2.33-2.42 \AA)$. The perfect tetrahedral ${ }^{1 / 2} \mathrm{Fe}_{\mathrm{s}}^{-}\left(T_{d}\right)$ defect is unstable - a symmetry-constrained relaxation of the structure gave a total energy $0.11 \mathrm{eV}$ above ${ }^{1 / 2} \mathrm{Fe}_{\mathrm{S}}^{-}\left(C_{2 v}\right)$. Considering the formation enthalpy difference of $\mathrm{Fe}_{\mathrm{i}}$ to $\mathrm{Fe}_{\mathrm{s}}(-0.5 \mathrm{eV})$, combined with a calculated formation enthalpy of $3.60 \mathrm{eV}$ for a neutral $\mathrm{Si}$ vacancy $(\mathrm{V})$, we estimate a binding energy between $\mathrm{Fe}_{\mathrm{S}}$ and $\mathrm{V}$ of about $3 \mathrm{eV}$. This means that if the concentration of vacancies is above the equilibrium level, ( $e x$. after electron irradiation), and if the temperature is such that the vacancies are mobile, a considerable fraction of $\mathrm{Fe}_{\mathrm{i}}$ will readily become substitutional, unless there is a high enough barrier or a more efficient trapping center for vacancies preventing the $\mathrm{Fe}_{\mathrm{i}}+\mathrm{V} \rightarrow \mathrm{Fe}_{\mathrm{s}}$ reaction from occurring. We will come back to this issue below.

The electronic structure of $\mathrm{Fe}_{\mathrm{s}}$ in $\mathrm{Si}$ is represented in Figure 4(c), and it is well described by the Watkins vacancy model. ${ }^{120}$ Accordingly, it results from the resonance between $t_{2}$ levels from the iron $3 d$ manifold and the $t_{2}$ levels from the Si vacancy. The result is the formation of a fully occupied $t_{2}^{6}$ bonding state (in the valence) along with an empty $t_{2}^{*}$ anti-bonding counterpart deep in the gap. The fully occupied $e$-component from the $3 d$ manifold of $\mathrm{Fe}$ is edging the valence band top. We note that (i) like the $t_{2}$ gap state in $\mathrm{Fe}_{\mathrm{i}}$, the $t_{2}^{*}$ state of $\mathrm{Fe}_{\mathrm{S}}$ is nodal on the $\mathrm{Fe}$ atom, but (ii) unlike in $\mathrm{Fe}_{\mathrm{i}}, t_{2}^{*}$ is reminiscent of the vacancy states and it is strongly localized on $\mathrm{Si}$ atoms.

Early calculations based on the Green's function method anticipated an inert $\mathrm{Fe}_{\mathrm{s}}$ center with no levels in the gap, ${ }^{121,122}$ i.e., the $e$ and $t_{2}^{*}$ states were predicted to lie below $E_{\mathrm{v}}$ and above $E_{\mathrm{c}}$, respectively. More recent density functional calculations placed the $t_{2}^{*}$ state well within the gap, and calculated an acceptor level either at $E_{\mathrm{c}}-0.41 \mathrm{eV}$ or $E_{\mathrm{c}}-0.29 \mathrm{eV}$, depending on the calculation specifics, such as the type of pseudopotentials and basis functions employed. ${ }^{25}$ These results challenge both theorists and experimentalists, suggesting that further studies should be carried out in order to identify the $\mathrm{Fe}_{\mathrm{s}}$ defect in Si. By comparing the electron affinity of $\mathrm{Fe}_{\mathrm{s}}$ and $\mathrm{Ti}_{\mathrm{i}}$ defects we arrive at an acceptor level for $\mathrm{Fe}_{\mathrm{S}}$ at $E_{\mathrm{c}}-0.20 \mathrm{eV}$, in line with Estreicher and co-workers ${ }^{25}$ who using a methodology much similar to ours obtained $\mathrm{Fe}_{\mathrm{s}}(-/ 0)$ at $E_{\mathrm{c}}-0.29 \mathrm{eV}$. Experimentally, there is not much data in the literature regarding the electrical levels of substitutional Fe. Perhaps the work by Kaminski et al. ${ }^{123}$ provide us what it could be a signature for this defect. Accordingly, a trap at $E_{\mathrm{c}}-0.38 \mathrm{eV}$ was assigned to an acceptor transition of $\mathrm{Fe}_{\mathrm{s}}$, although this link was solely based on annealing and concentration arguments. ${ }^{123,124}$ Our calculated $\mathrm{Fe}_{\mathrm{s}}(-/ 0)$ transition is about $0.2 \mathrm{eV}$ off the aforementioned trap, which is about the expected error of the marker method if the electronic structure of the marker is far from that of the defect under scrutiny. Here we are comparing an acceptor transition of a defect which very much resembles the vacancy electronic structure $\left(\mathrm{Fe}_{\mathrm{s}}\right)$ with an another acceptor transition involving electron capture at the $3 \mathrm{~d}$ level of interstitial Ti. However, comparing electron affinities of $\mathrm{Cu}_{\mathrm{s}}(-/ 0)$ and $\mathrm{Cu}_{\mathrm{s}}(=/-)$ with those of $\mathrm{Fe}_{\mathrm{s}}(-/ 0)$ and $\mathrm{Fe}_{\mathrm{s}}(=/-)$ we obtain levels at $E_{\mathrm{c}}-0.34 \mathrm{eV}$ (close to Kaminski's trap at $\left.E_{\mathrm{c}}-0.38 \mathrm{eV}\right)^{123}$ and $E_{\mathrm{c}}+0.11 \mathrm{eV}$ respectively, indicat- 
ing that $\mathrm{Fe}_{\mathrm{S}}$ only has one acceptor level within the gap. While these results are consistent with those obtained using the $\mathrm{Ti}_{\mathrm{i}}(-/ 0)$ marker, due to similarities between $\mathrm{Cu}_{\mathrm{s}}$ and $\mathrm{Fe}_{\mathrm{s}}$ centers we anticipate that the $\mathrm{Cu}_{\mathrm{s}}$-marked $\mathrm{Fe}_{\mathrm{S}}(-/ 0)$ level is likely to be our best estimate.

The calculated isomer shifts of neutral and negatively charged $\mathrm{Fe}_{\mathrm{s}}$ are $-0.13 \mathrm{~mm} / \mathrm{s}$ and $-0.11 \mathrm{~mm} / \mathrm{s}$, respectively. Their magnitude is slightly overestimated with respect to the measurements, but unlike previous calculations, ${ }^{41}$ we obtain the right sign, meaning that the contact density on $\mathrm{Fe}_{\mathrm{s}}$ is slightly higher than in $\alpha$ $\mathrm{Fe}$, most probably due to the additional electrons from the $a_{1}$ vacancy state (see Fig. 4(c)). Notably, like in $\mathrm{Fe}_{\mathrm{i}}$, the charge state dependence of the isomer shift is rather small - the capture of an electron by $\mathrm{Fe}_{\mathrm{s}}^{0}$ changes $\delta$ by only $0.02 \mathrm{~mm} / \mathrm{s}$, again due to the fact that the $4 \mathrm{~s}$ state of iron in $\mathrm{Fe}_{\mathrm{s}}$ is empty (the oxidation state is 0 ) and the $t_{2}^{*}$ acceptor state is nodal on Fe.

\section{Iron-vacancy pair}

We investigated the $\mathrm{Fe}_{\mathrm{i}} \mathrm{V}$ pair by first looking at its ground state electronic structure, and then by inspecting its stability against transformation to substitutional $\mathrm{Fe}$, i.e. by following the reaction $\mathrm{Fe}_{\mathrm{i}}+\mathrm{V} \rightarrow \mathrm{Fe}_{\mathrm{s}}$. The lowest energy structure of $\mathrm{Fe}_{\mathrm{i}} \mathrm{V}$, made of separate $\mathrm{Fe}_{\mathrm{i}}$ and $\mathrm{V}$ defects, was that of a $\mathrm{Fe}_{i}$ with a missing $\mathrm{Si}$ nearest neighbor along $\langle 111\rangle$. Ground states were all low-spin ${ }^{1 / 2}\left\{\mathrm{Fe}_{\mathrm{i}} \mathrm{V}\right\}^{+},{ }^{0}\left\{\mathrm{Fe}_{\mathrm{i}} \mathrm{V}\right\}^{0}$ and ${ }^{1 / 2}\left\{\mathrm{Fe}_{\mathrm{i}} \mathrm{V}\right\}^{-}$, while higher-spin states ${ }^{3 / 2}\left\{\mathrm{Fe}_{\mathrm{i}} \mathrm{V}\right\}^{+},{ }^{1}\left\{\mathrm{Fe}_{\mathrm{i}} \mathrm{V}\right\}^{0}$ and ${ }^{3 / 2}\left\{\mathrm{Fe}_{\mathrm{i}} \mathrm{V}\right\}^{-}$ where metastable by $0.17 \mathrm{eV}, 0.21 \mathrm{eV}$ and $0.45 \mathrm{eV}$, respectively. Placing the vacancy at the second nearest neighboring site along $\langle 100\rangle$ to the $\mathrm{Fe}$ atom resulted in $\left\{\mathrm{Fe}_{\mathrm{i}}-\mathrm{Si}-\mathrm{V}\right\}^{+, 0,-}$ structures with spin $1 / 2,0$ and $1 / 2$ and relative energy $1.18 \mathrm{eV}, 1.33 \mathrm{eV}$ and $1.47 \mathrm{eV}$ above their respective $\mathrm{Fe}_{\mathrm{i}} \mathrm{V}$ ground states (and respective charge states). These figures are still low when compared with the $\sim 3 \mathrm{eV}$ binding energy of $\mathrm{Fe}_{\mathrm{s}}$ from infinitely separated $\mathrm{V}$ and $\mathrm{Fe}_{\mathrm{i}}$ defects (see above).

In order to follow the energetics of the $\mathrm{Fe}_{\mathrm{i}}+$ $\mathrm{V} \rightarrow \mathrm{Fe}_{\mathrm{s}}$ reaction we employed the nudged elastic band method ${ }^{125,126}$ on a two-step process, namely (1) $\mathrm{Fe}_{\mathrm{i}}-\mathrm{Si}-\mathrm{V} \rightarrow \mathrm{Fe}_{\mathrm{i}} \mathrm{V}$ and $(2) \mathrm{Fe}_{\mathrm{i}} \mathrm{V} \rightarrow \mathrm{Fe}_{\mathrm{s}}$. A total of 9 intermediate structures (images) were considered between the reactant/product structures from each step. We assume that in the presence of vacancies, the eventual formation of $\left\{\mathrm{Fe}_{\mathrm{i}}-\mathrm{Si}-\mathrm{V}\right\}$ is limited by an activation energy that corresponds to the migration barrier of the vacancy. This barrier depends on the charge state of the traveling $\mathrm{V}$ defect and was accurately measured by Watkins as $0.33 \mathrm{eV}, 0.45 \mathrm{eV}$ and $0.18 \mathrm{eV}$ for $\mathrm{V}^{++}, \mathrm{V}^{0}$ and $\mathrm{V}^{=},{ }^{120}$ respectively. Such low values imply that $\left\{\mathrm{Fe}_{\mathrm{i}}-\mathrm{Si}-\mathrm{V}\right\}$ should form before $\mathrm{Fe}_{\mathrm{i}}$ becomes mobile, even below room temperature. For reaction (1) we obtained barriers of $0.2 \mathrm{eV}$, $0.18 \mathrm{eV}$ and $0.18 \mathrm{eV}$ for positively charged, neutral and negatively charged supercells (spin $1 / 2,0$ and $1 / 2$ ), respectively. For step (2) we obtain barriers of $0.17 \mathrm{eV}$,
$0.18 \mathrm{eV}$ and $0.15 \mathrm{eV}$, again for charge states,+ 0 and - , respectively (spin $1 / 2,0$ and $1 / 2$ ). These results are in apparent disagreement with those from Ref. 25 where a barrier above $0.45 \mathrm{eV}$ was reported. However we note we are comparing two different mechanisms. In Ref. 25 a series of molecular dynamics runs were performed in which the Si atoms in the supercell were allowed to relax but the Fe atom was forced to move at constant speed along a trigonal axis, starting at the second neighboring tetrahedral interstitial site (from V) over the hexagonal site to the nearest neighboring $\mathrm{T}$ site, and finally into the vacancy site. In our opinion, this approach unjustifiably assumes that the moving defect is Fe (while $\mathrm{V}$ is assumed to be static).

Our predicted barriers are not compatible with a $\mathrm{Fe}_{\mathrm{i}} \mathrm{V}$ complex stable up to $500^{\circ} \mathrm{C}$ as reported in Ref. 127 and references therein, neither support the early assignment of the EPR NL19 signal to $\mathrm{Fe}_{\mathrm{i}} \mathrm{V}$, which was then shown to be stable at least up to $160^{\circ} \mathrm{C} .{ }^{128}$ Although the ${ }^{3 / 2}\left\{\mathrm{Fe}_{\mathrm{i}} \mathrm{V}\right\}^{+}$candidate is only $0.17 \mathrm{eV}$ less stable than $1 / 2\{\mathrm{Fe}-\mathrm{V}\}^{+}$, we did not find a stable alternative spin- $3 / 2$ $\mathrm{Fe}_{\mathrm{i}} \mathrm{V}$ defect that could be connected to NL19. Based on the above results, our view is that $\mathrm{Fe}_{\mathrm{i}} \mathrm{V}$ will not survive at room temperature and above, and that NL19 could be related to a more stable vacancy- $\mathrm{Fe}_{\mathrm{i}}$ complex (also involving a single $\mathrm{Fe}$ atom), with ${ }^{3 / 2} \mathrm{Fe}_{\mathrm{i}} \mathrm{V}_{2}^{-}$being a likely candidate (see below).

\section{E. Iron-divacancy pair in Si}

Here we focus mostly on the stable iron-divacancy $\left(\mathrm{Fe}_{\mathrm{i}} \mathrm{V}_{2}\right)$ structure which, as reported in Ref. 25, consists on a Fe atom right at the center of a divacancy (at the bond-center site of the otherwise perfect $\mathrm{Si}$ lattice). Accordingly, we obtain ${ }^{1 / 2} \mathrm{Fe}_{\mathrm{i}} \mathrm{V}_{2}^{+},{ }^{1} \mathrm{Fe}_{\mathrm{i}} \mathrm{V}_{2}^{0},{ }^{3 / 2} \mathrm{Fe}_{\mathrm{i}} \mathrm{V}_{2}^{-}$and ${ }^{1} \mathrm{Fe}_{\mathrm{i}} \mathrm{V}_{2}$, all trigonal structures with $D_{3 d}$ symmetry. Alternative spin configurations ${ }^{3 / 2} \mathrm{Fe}_{\mathrm{i}} \mathrm{V}_{2}^{+},{ }^{2} \mathrm{Fe}_{\mathrm{i}} \mathrm{V}_{2}^{0},{ }^{1 / 2} \mathrm{Fe}_{\mathrm{i}} \mathrm{V}_{2}^{-}$

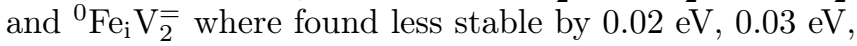
$0.12 \mathrm{eV}$ and $0.37 \mathrm{eV}$, respectively.

As depicted in Figure 4(d), the electronic structure of $\mathrm{Fe}_{\mathrm{i}} \mathrm{V}_{2}$ results from the overlap of the $3 \mathrm{~d}$ states of the Fe atom $\left(2 e_{g}+a_{1 g}\right.$ in a $D_{3 d}$ representation) with the $e_{g}$ and $e_{u}$ state of the Si divacancy. The $e_{g}$ states from both defects mix strongly, resulting in bonding and antibonding levels in the valence and conduction bands, respectively. The formation energy of a neutral $\mathrm{Fe}_{\mathrm{i}} \mathrm{V}_{2}$ is $5.47 \mathrm{eV}$, which along with the calculated formation energies for $\mathrm{Fe}_{\mathrm{S}}$ and $\mathrm{V}$ gives a binding energy of $1.33 \mathrm{eV}$ for the reaction $\mathrm{Fe}_{\mathrm{s}}+\mathrm{V} \rightarrow \mathrm{Fe}_{\mathrm{i}} \mathrm{V}_{2}$. This figure is not far from the $1.56 \mathrm{eV}$ previously found by the Estreicher group, ${ }^{25}$ and suggests that this is a strong defect that can survive well above room temperature.

Other structures for $\mathrm{Fe}_{\mathrm{i}} \mathrm{V}_{2}$ were investigated. The asymmetric structure with the Fe atom located at one of the vacant sites $\left(\mathrm{Fe}_{\mathrm{S}} \mathrm{V}\right.$ structure) was unstable - upon relaxation, the Fe atom moved without an impeding barrier to the bond center site between the two vacancies. 
Other structures like $\mathrm{Fe}_{\mathrm{s}}-\mathrm{Si}-\mathrm{V}$ or $\mathrm{Fe}_{\mathrm{s}}-\mathrm{Si}-\mathrm{Si}-\mathrm{V}$, where a vacancy is located at the second and third neighboring site to $\mathrm{Fe}_{\mathrm{s}}$ were found to be $0.98 \mathrm{eV}$ and $1.26 \mathrm{eV}$ above the ground state.

Also in agreement with the authors of Ref. 25 we found that $\mathrm{Fe}_{\mathrm{i}} \mathrm{V}_{2}$ (with $D_{3 d}$ symmetry) is not a donor but rather a multiple acceptor. While they report a $(-/ 0)$ level at $E_{\mathrm{c}}-0.73 \mathrm{eV}$ or $E_{\mathrm{c}}-0.64 \mathrm{eV}$ (depending on the method specifics), we obtain a first acceptor level at $E_{\mathrm{c}}-0.92 \mathrm{eV}$ using the $\mathrm{Ti}_{\mathrm{i}}$-marker. The use of the more suitable $\mathrm{Cu}_{\mathrm{s}}$ marker gives $\mathrm{Fe}_{\mathrm{i}} \mathrm{V}_{2}(-/ 0)=E_{\mathrm{v}}+0.10 \mathrm{eV}$ and $\mathrm{Fe}_{\mathrm{i}} \mathrm{V}_{2}(=/-)=E_{\mathrm{v}}+0.41 \mathrm{eV}$. Recently, Tang and co-workers ${ }^{129}$ reported electrical measurements in p-type electron-irradiated Si contaminated with Fe. From a series of 30 -min isochronal anneals they found that above $T \approx 150^{\circ} \mathrm{C}$ mobile $\mathrm{Fe}_{\mathrm{i}}$ could interact with divacancies to form a hole trap at $E_{\mathrm{v}}+0.29 \mathrm{eV}$ (labeled H29) which was connected to a metastable $\mathrm{Fe}_{\mathrm{i}}-\mathrm{V}_{2}$ complex. By rising the annealing temperature above $T \approx 200^{\circ} \mathrm{C}$ the $\mathrm{H} 29$ signal transformed to a more stable and deeper hole trap (H34) at $E_{\mathrm{v}}+0.34 \mathrm{eV}$, which was assigned to the $D_{3 d^{-}}$ symmetric $\mathrm{Fe}_{\mathrm{i}}-\mathrm{V}_{2}$ defect. While its was not possible to establish the charge states involved in the H34 transition, our calculations strongly suggest that it relates to $\mathrm{Fe}_{\mathrm{i}} \mathrm{V}_{2}(=/-)$.

The calculated Mössbauer parameters of $\mathrm{Fe}_{\mathrm{i}} \mathrm{V}_{2}$ are reported in Table III. Being a non-cubic center, it should give rise to a quadrupole splitting in the MS signal. Accordingly, for the neutral and negatively charged defects we anticipate resonance speeds of $\delta=0.35 \mathrm{~mm} / \mathrm{s}$ and $\delta=0.39 \mathrm{~mm} / \mathrm{s}$ for the centroid, and splittings $\Delta=1.1 \mathrm{~mm} / \mathrm{s}$ and $\Delta=0.4 \mathrm{~mm} / \mathrm{s}$, respectively. Analogously to previous Fe-related defects, the change of $\delta$ values upon charge state transition is small. On the other hand, the quadrupole splitting decreases by more that $50 \%$ upon electron capture by $\left\{\mathrm{Fe}_{\mathrm{i}} \mathrm{V}\right\}^{0}$. This effect comes from the occupation of an $a_{1 g}$ axial state centered on the Fe atom. We note that $\left\{\mathrm{Fe}_{\mathrm{i}} \mathrm{V}\right\}^{-}$, which is expected to be particularly stable in high-resistivity p-type and intrinsic material, should give rise to resonances close to $0.8 \mathrm{~mm} / \mathrm{s}$ and $-0.1 \mathrm{~mm} / \mathrm{s}$. These coincide with the isomer shifts of $\mathrm{Fe}_{\mathrm{i}}$ and $\mathrm{Fe}_{\mathrm{s}}$, which may mask (or even undermine) the analysis of the experimental data, particularly in the case where ion implantation has been utilized to introduce the ${ }^{57} \mathrm{Fe}$ species.

\section{IRON IN OTHER GROUP-IV SEMICONDUCTORS}

Mössbauer parameters were also calculated for elemental $\mathrm{Fe}_{\mathrm{s}}$ and $\mathrm{Fe}_{\mathrm{i}}$ defects in other group-IV materials, namely in Ge, Diamond, 3C-SiC (cubic phase) and in Sirich $\mathrm{SiGe}$ alloys. Like in $\mathrm{Si}$, the defects were found to minimize the total energy in the ${ }^{0} \mathrm{Fe}_{\mathrm{s}}^{0}\left(T_{d}\right)$ and ${ }^{1} \mathrm{Fe}_{\mathrm{i}}^{0}\left(T_{d}\right)$ states. The distance between $\mathrm{Fe}$ and its nearest neighbors expanded relative to the unrelaxed values, except for $\mathrm{Fe}_{\mathrm{S}}$ in $\mathrm{Si}$ and $\mathrm{Ge}$ (where it contracted) and $\mathrm{Fe}_{\mathrm{C}}$ in 3C-SiC (where it remained effectively unaltered).
Overall, there is good agreement between the isomer shifts observed in Ge, Diamond and SiC, collected in Table I, and those from our calculations reported in Table IV. As depicted in Figure 6 and in agreement with Ref. 37, we found an approximate linear trend between IS values and the distance between $\mathrm{Fe}$ and its first neighbors. IS values for $\mathrm{Fe}_{\mathrm{i}}$ in $\mathrm{Ge}$, Diamond and $\mathrm{Fe}_{\mathrm{i}, \mathrm{C}}$ in $\mathrm{SiC}$ match the experimental results, and for all other IS values the agreement is within $0.04 \mathrm{~mm} / \mathrm{s}$ and $0.14 \mathrm{~mm} / \mathrm{s}$. It is noted that, while the IS obtained for $\mathrm{Fe}_{\mathrm{s}}$ in Diamond deviates markedly from previous calculations, ${ }^{38}$ the difference between the calculation methods most likely accounts for this discrepancy. Notably, the relaxed $\mathrm{Fe}_{\mathrm{i}}-\mathrm{C}$ and $\mathrm{Fe}_{\mathrm{s}}-\mathrm{C}$ distances in Diamond were effectively equal, yet $\delta\left(\mathrm{Fe}_{\mathrm{i}}\right)$ and $\delta\left(\mathrm{Fe}_{\mathrm{s}}\right)$ are $1.08 \mathrm{~mm} / \mathrm{s}$ apart. However, as we move towards heavier elements, the relative differences between $\delta\left(\mathrm{Fe}_{\mathrm{i}}\right)$ and $\delta\left(\mathrm{Fe}_{\mathrm{s}}\right)$ decrease with increasing distance between $\mathrm{Fe}$ and its neighbors, to a minimum value of $0.76 \mathrm{~mm} / \mathrm{s}$ calculated for Ge.

To the best of our knowledge, $\delta\left(\mathrm{Fe}_{\mathrm{C}}\right)$ in $\mathrm{SiC}$ has not been determined experimentally. We obtain $\delta\left(\mathrm{Fe}_{\mathrm{C}}\right)=-0.65 \mathrm{~mm} / \mathrm{s}$, which is about the same value previously calculated for $\mathrm{Fe}_{\mathrm{C}}$ in $6 \mathrm{H}-\mathrm{SiC}{ }^{39}$ We note though, that experimental IS resonances for substitutional and interstitial $\mathrm{Fe}$ in both $6 \mathrm{H}-\mathrm{SiC}$ and $3 \mathrm{C}$ $\mathrm{SiC}$ follow similar trends. ${ }^{36}$ Following the methodology outlined in Section IID, formation energy calculations for $\mathrm{Fe}_{\mathrm{Si}}$ and $\mathrm{Fe}_{\mathrm{C}}$ in $3 \mathrm{C}-\mathrm{SiC}$ cubic supercells, yielded $E_{\mathrm{f}}\left(\mathrm{Fe}_{\mathrm{Si}}\right)=2.99 \mathrm{eV}, 2.72 \mathrm{eV}$ and $3.26 \mathrm{eV}$, and $E_{\mathrm{f}}\left(\mathrm{Fe}_{\mathrm{C}}\right)=4.78 \mathrm{eV}, 5.05 \mathrm{eV}$ and $4.51 \mathrm{eV}$ under stoichiometric, Si-rich and C-rich crystal growth conditions respectively. As $E_{\mathrm{f}}\left(\mathrm{Fe}_{\mathrm{Si}}\right)$ is between $1.2 \mathrm{eV}$ and $2.3 \mathrm{eV}$ lower than $E_{\mathrm{f}}\left(\mathrm{Fe}_{\mathrm{C}}\right)$, it suggests a preferential incorporation of Fe in the Si sites, allowing us to assign the observed peak at $\delta=-0.23 \mathrm{~mm} / \mathrm{s}$ reported in Ref. 36 to $\mathrm{Fe}_{\mathrm{Si}}$ (compared to the calculated value of $-0.27 \mathrm{~mm} / \mathrm{s}$ ).

Formation energies were also calculated for interstitial iron in $\mathrm{SiC}$, where $E_{\mathrm{f}}\left(\mathrm{Fe}_{\mathrm{i}, \mathrm{C}}\right)=4.85 \mathrm{eV}$ and $E_{\mathrm{f}}\left(\mathrm{Fe}_{\mathrm{i}, \mathrm{Si}}\right)=$ $5.74 \mathrm{eV}$, indicating a preference for sites with firstneighboring $\mathrm{C}$ atoms. This result explains the transformation of the $\mathrm{Fe}_{\mathrm{i}, 2}$ peak to the $\mathrm{Fe}_{\mathrm{i}, 1}$ peak observed in Ref. 36 upon annealing the SiC samples, allowing us to assign $\mathrm{Fe}_{\mathrm{i}, 1}$ and $\mathrm{Fe}_{\mathrm{i}, 2}$ peaks to $\mathrm{Fe}_{\mathrm{i}, \mathrm{C}}$ and $\mathrm{Fe}_{\mathrm{i}, \mathrm{Si}}$, respectively.

For Si-rich SiGe alloys, the Mössbauer parameters were studied as a function of the distance between a $\mathrm{Fe}_{\mathrm{S}}\left(\mathrm{Fe}_{\mathrm{i}}\right)$ defect and a neighboring substitutional Ge atom (from first to fourth neighboring distance). The presence of the Ge atom produced a deformation of the local electron density in all cases. The values of the IS and QS for $\mathrm{Fe}_{\mathrm{i}}$ and $\mathrm{Fe}_{\mathrm{s}}$ decrease monotonically with the distance between the Fe impurity and the Ge atom, and both $\delta\left(\mathrm{Fe}_{\mathrm{i}}\right)$ and $\delta\left(\mathrm{Fe}_{\mathrm{s}}\right)$ are very similar to values calculated in bulk $\mathrm{Si}$. Interestingly, the QS for $\mathrm{Fe}_{i}$ with a $\mathrm{Ge}$ first neighbor is $1.25 \mathrm{~mm} / \mathrm{s}$, about seven times the value obtained with a Ge fourth neighbor. However, the relative energies obtained from PAW calculations for second, third and fourth neighboring $\mathrm{Fe}_{\mathrm{i}}$-Ge pairs are $-0.12 \mathrm{eV}$, 


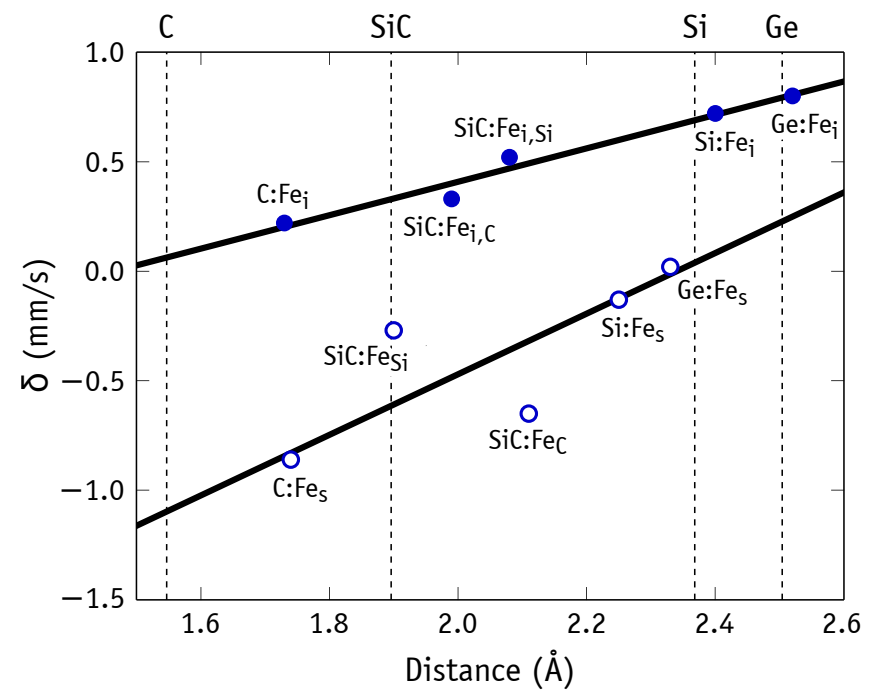

Figure 6. IS as a function of the distance between Fe and its first neighbors for $\mathrm{Fe}_{\mathrm{s}}$ and $\mathrm{Fe}_{\mathrm{i}}$ defects in Diamond, Ge, Si and $3 \mathrm{C}-\mathrm{SiC}$. Vertical dashed lines indicate the bond lengths in the corresponding bulk semiconductors.

$-0.17 \mathrm{eV}$ and $-0.17 \mathrm{eV}$, with respect to the first neighboring pair, allowing us to conclude that $\mathrm{Fe}_{i}$ atoms will effectively avoid Ge atoms in the alloy. Hence, the Mössbauer spectrum of $\mathrm{Fe}_{\mathrm{i}}$ in $\mathrm{Si}$-rich $\mathrm{SiGe}$ alloys is expected to be analogous to the signal in bulk $\mathrm{Si}$, although broadened by quadrupole splittings of remote $\mathrm{Fe}_{\mathrm{i}}-\mathrm{Ge}$ pairs and internal strain fields. For $\mathrm{Fe}_{\mathrm{s}}$, structures with Ge atoms at first to fourth neighboring sites have essentially the same small relative energies (within $0.03 \mathrm{eV}$ ), suggesting that in principle there will be no preferential distribution of $\mathrm{Fe}_{\mathrm{s}}$ with respect to the location of the Ge minority species. However, due to a sizable QS for Ge at first and second nearest neighboring positions, considerable differences are expected in the corresponding Mössbauer spectra with respect to the bulk Si measurements. Obviously these deviations will depend on the fraction of the $\mathrm{Ge}$ concentration with respect to that of $\mathrm{Si}$.

\section{CONCLUSIONS}

In this work we combined pseudopotential and allelectron density functional calculations of Fe-related defects in group-IV semiconductors (mostly in $\mathrm{Si}$, but also in $\mathrm{Ge}, \mathrm{C}, \mathrm{SiC}$ and Si-rich SiGe alloys). Our aim was to investigate electronic and electron-nuclear coupling properties, and compare them to those measured with several spectroscopic techniques, Mössbauer Spectroscopy in particular.

After a short review of previous experimental and theoretical reports on ${ }^{57} \mathrm{Fe}$ Mössbauer parameters for Ferelated defects in group-IV semiconductors, we described the theoretical methodologies employed by us. This includes methods to obtain defect structures, total energies
Table IV. Calculated IS ( $\delta$ in $\mathrm{mm} / \mathrm{s})$ and QS $(\Delta$ in $\mathrm{mm} / \mathrm{s})$ values for $\mathrm{Fe}_{\mathrm{i}}$ and $\mathrm{Fe}_{\mathrm{s}}$ defects in Ge, C, 3C-SiC and SiGe alloys. For the latter material, numbered rows 1, 2, 3 and 4 refer to first, second, third and fourth neighboring Fe-Ge pairs.

\begin{tabular}{|c|c|c|c|c|c|}
\hline & & $\delta\left(\mathrm{Fe}_{\mathrm{i}}\right)$ & $\delta\left(\mathrm{Fe}_{\mathrm{s}}\right)$ & $\Delta\left(\mathrm{Fe}_{\mathrm{i}}\right)$ & $\Delta\left(\mathrm{Fe}_{\mathrm{s}}\right)$ \\
\hline $\mathrm{C}$ & & 0.22 & -0.86 & & \\
\hline $\mathrm{SiC}$ & $\left(\mathrm{Fe}_{\mathrm{i}, \mathrm{Si}} / \mathrm{Fe}_{\mathrm{C}}\right)$ & 0.52 & -0.27 & & \\
\hline & $\left(\mathrm{Fe}_{\mathrm{i}, \mathrm{C}} / \mathrm{Fe}_{\mathrm{Si}}\right)$ & 0.33 & -0.65 & & \\
\hline $\mathrm{SiGe}$ & 1 & 0.71 & -0.13 & 1.25 & 1.55 \\
\hline & 2 & 0.69 & -0.17 & 0.19 & 0.42 \\
\hline & 3 & 0.69 & -0.16 & 0.19 & 0.10 \\
\hline & 4 & 0.69 & -0.16 & 0.17 & 0.01 \\
\hline $\mathrm{Ge}$ & & 0.80 & 0.02 & & \\
\hline
\end{tabular}

and electron densities (PAW and APW+lo methods), to calculate isomer shifts and quadrupole splittings, formation energies and charge transition levels.

We provided a detailed description of the calculation of the Mössbauer calibration constants, $\alpha$ and $Q$. These quantities allowed us to obtain the isomer shifts and quadrupole splittings from the contact densities and electric field gradients calculated from first-principles. To this end, we calculated relative contact densities and EFG values for $\mathrm{Fe}$ in a comprehensive set of Fe-related compounds, and established linear relations with corresponding IS and QS values obtained experimentally. The resulting values $\alpha=0.26 \mathrm{Bohr}^{3} \mathrm{~mm} / \mathrm{s}$ and $Q=0.17 \mathrm{~b}$ agree well with previous calculations reported in the literature.

We devoted Section III to the study of Fe defects in Si. We started by looking at the relative stability and upper concentration limit of interstitial iron relative to that of substitutional iron in $\mathrm{Si}$ (assuming equilibrium conditions across a $\mathrm{Si} / \beta-\mathrm{FeSi}_{2}$ interface). We found an enthalpy of formation for $\mathrm{Fe}_{\mathrm{i}}$ of $2.73 \mathrm{eV}$, which is only $0.14 \mathrm{eV}$ below the figure obtained from EPR experiments ${ }^{27}$ and only $0.5 \mathrm{eV}$ lower than the enthalpy of formation of $\mathrm{Fe}_{\mathrm{s}}$, suggesting that the concentration of the latter defect could be relevant, particularly in n-type $\mathrm{Si}$, where it could act as a strong recombination center for minority carriers in solar material.

Looking more closely at the $\mathrm{Fe}_{\mathrm{i}}$ impurity, we confirm that it gives rise to a single donor level, calculated at $E_{\mathrm{v}}+0.33 \mathrm{eV}$ (only $0.05 \mathrm{eV}$ below the well established transition measured by DLTS ${ }^{8,9}$ ). Inspection of further ionization and a comparison with the $\mathrm{Fe}_{\mathrm{i}} \mathrm{B}_{\mathrm{s}}$ defect allowed us to conclude that $\mathrm{Fe}_{\mathrm{i}}(+/++)$ is resonant with the valence of the host. The calculated isomer shifts of neutral and positively charged $\mathrm{Fe}_{i}$ in $\mathrm{Si}$ are calculated as $0.72 \mathrm{~mm} / \mathrm{s}$ and $0.67 \mathrm{~mm} / \mathrm{s}$, respectively. We attribute the rather small charge dependence of the IS to the nodal character of the $3 \mathrm{~d}$ level on $\mathrm{Fe}$ (which is the one involved in the donor transition), but also to the fact that the $\mathrm{Fe}$ atom is in the 0 oxidation state, leaving the $4 \mathrm{~s}$ state (with 
amplitude on $\mathrm{Fe}$ ) empty during the $(0 /+)$ transition. The agreement between the calculated IS for $\mathrm{Fe}_{i}^{+}$and the available Mössbauer data in p-type $\mathrm{Si}$ is good. On the other hand, for the neutral charge state, experiments came up with two rather different values, $\delta=0.40 \mathrm{~mm} / \mathrm{s}$ or $0.77 \mathrm{~mm} / \mathrm{s}$, clearly suggestion that further work is necessary in order to clarify the picture.

The iron-boron pair was also investigated. We started by looking at the electronic structure and levels of the most stable form of this defect, where the $\mathrm{B}$ atom replaces a Si first neighbor of the $\mathrm{Fe}_{\mathrm{i}}$ defect (trigonal structure). In agreement with DLTS measurements we obtained donor and acceptor levels at $E_{\mathrm{v}}+0.20 \mathrm{eV}$ and $E_{\mathrm{c}}-0.35 \mathrm{eV}$, respectively. The IS values for the $\mathrm{Fe}_{\mathrm{i}} \mathrm{B}_{\mathrm{s}}$ pairs in charge state $q$ are found to be rather close to those of $\mathrm{Fe}_{\mathrm{i}}$ in the $q+1$ charge state. This supports the model for the FeB pair as a Coulomb-stabilized complex composed by a $\mathrm{Fe}_{\mathrm{i}}^{+}$cation next to a $\mathrm{B}_{\mathrm{s}}^{-}$anion.

We confirm previous calculations ${ }^{25}$ where $\mathrm{Fe}_{\mathrm{S}}$ was predicted to be a deep acceptor. Our calculations indicate a $\mathrm{Fe}_{\mathrm{s}}(-/ 0)$ level at $0.38 \mathrm{eV}$ below $E_{\mathrm{c}}$. The calculated value for the IS of $\mathrm{Fe}_{\mathrm{s}}$ was $-0.13 \mathrm{~mm} / \mathrm{s}$, in line with the generally accepted value assigned to $\mathrm{Fe}_{\mathrm{s}}(-0.04 \mathrm{~mm} / \mathrm{s})$ in Mössbauer measurements. We also confirm that there is a strong binding energy between $\mathrm{Fe}_{i}$ and a $\mathrm{Si}$ vacancy. The reaction $\mathrm{Fe}_{\mathrm{i}}+\mathrm{V} \rightarrow \mathrm{Fe}_{\mathrm{s}}$ was found to realease about $3 \mathrm{eV}$. We investigated this reaction in-depth using the nudged elastic band method. In disagreement with the prevalent view, we concluded that the reaction kinetics is effectively limited by the migration rate of the vacancy, meaning that several spectroscopic signals (including the NL19 center from EPR), which were detected above room-temperature, were incorrectly connected to an iron-vacancy pair.

Our final analysis concerned the iron-divacancy pair $\left(\mathrm{Fe}_{\mathrm{i}} \mathrm{V}_{2}\right)$ in $\mathrm{Si}$, comprising a $\mathrm{Fe}$ atom at the center of a divacancy. The $\mathrm{Fe}_{\mathrm{i}} \mathrm{V}_{2}$ defect was predicted to be a very deep double acceptor with levels at $\mathrm{Fe}_{\mathrm{i}} \mathrm{V}_{2}(-/ 0)=$ $E_{\mathrm{v}}+0.10 \mathrm{eV}$ and $\mathrm{Fe}_{\mathrm{i}} \mathrm{V}_{2}(-/ 0)=E_{\mathrm{v}}+0.41 \mathrm{eV}$. We concluded that this is a rather stable complex and should be dominant in the presence of vacancies, both after sample quenching from high temperatures, and in samples that were subject to irradiation with electrons and heavier particles. We anticipate that the Mössbauer signal for the neutral complex is a doublet centered at $\delta=0.35 \mathrm{~mm} / \mathrm{s}$ and split by $\Delta=1.1 \mathrm{~mm} / \mathrm{s}$. In the negative charge state the centroid increases slightly to $0.39 \mathrm{~mm} / \mathrm{s}$ but the density becomes more isotropic with $\Delta=0.4 \mathrm{~mm} / \mathrm{s}$.

Finally, we studied the Mössbauer parameters for $\mathrm{Fe}_{\mathrm{i}}$ and $\mathrm{Fe}_{\mathrm{s}}$ in $\mathrm{Ge}$, diamond, 3C-SiC and Si-rich SiGe alloys. We confirm the observed approximate linear dependence of the IS with the distance between Fe and its first neighbors. The agreement between theory and experiments is very good in general. Additionally, we fill in some blanks and improve upon some previous calculations. This includes the assignment of $\mathrm{Fe}_{\mathrm{S}}$ and $\mathrm{Fe}_{\mathrm{i}}$ defects with specific neighbors in $\mathrm{SiC}$, as well as the IS for $\mathrm{Fe}_{\mathrm{s}}$ in diamond.

\section{ACKNOWLEDGEMENTS}

JC thanks Prof. Yutaka Yoshida for many fruitful discussions. This work was funded by the Fundação para a Ciência e a Tecnologia (FCT) under projects PTDC/CTM-ENE/1973/2012 and UID $/ \mathrm{CTM} / 50025 / 2013$, and funded by FEDER funds through the COMPETE 2020 Program. The authors would like to acknowledge the contribution of the COST Action MP1406. Computer resources were provided by the Swedish National Infrastructure for Computing (SNIC) at PDC.

\section{REFERENCES}

${ }^{1}$ A. Istratov, T. Buonassisi, M. Pickett, M. Heuer, and E. Weber, Materials Science and Engineering: B 134, 282 (2006).

${ }^{2}$ T. Buonassisi, A. A. Istratov, M. Heuer, M. A. Marcus, R. Jonczyk, J. Isenberg, B. Lai, Z. Cai, S. Heald, W. Warta, R. Schindler, G. Willeke, and E. R. Weber, Journal of Applied Physics 97, 074901 (2005).

${ }^{3}$ A. A. Istratov, H. Hieslmair, and E. R. Weber, Applied Physics A 69, 13 (1999).

${ }^{4}$ A. A. Istratov, H. Hieslmair, and E. R. Weber, Applied Physics A 70, 489 (2000).

${ }^{5}$ H. H. Woodbury and G. W. Ludwig, Phys. Rev. 117, 102 (1960).

${ }^{6}$ E. Sieverts, S. Muller, C. Ammerlaan, and E. Weber, Solid State Communications 47, 631 (1983).

${ }^{7}$ S. Greulich-Weber, J. R. Niklas, E. R. Weber, and J. M. Spaeth, Physical Review B 30, 6292 (1984).

${ }^{8}$ H. Feichtinger, J. Waltl, and A. Gschwandtner, Solid State Communications 27, 867 (1978).

${ }^{9}$ K. Wünstel and P. Wagner, Applied Physics A 27, 207 (1982).

${ }^{10}$ U. Wahl, J. G. Correia, E. Rita, J. P. Araújo, and J. C. Soares (The ISOLDE Collaboration), Phys. Rev. B 72, 014115 (2005).

${ }^{11}$ D. J. Silva, U. Wahl, J. G. Correia, and J. P. Araújo, Journal of Applied Physics 114, 103503 (2013).

${ }^{12} \mathrm{H}$. Gunnlaugsson, G. Weyer, N. Christensen, M. Dietrich, M. Fanciulli, K. Bharuth-Ram, R. Sielemann, A. Svane, and t. ISOLDE Collaboration, Physica B: Condensed Matter 340342, 532 (2003).

${ }^{13}$ Y. Yoshida, Y. Kobayashi, K. Hayakawa, K. Yukihira, A. Yoshida, H. Ueno, F. Shimura, and F. Ambe, Physica B: Condensed Matter 376-377, 69 (2006).

${ }^{14}$ D. Macdonald, T. Roth, P. N. K. Deenapanray, K. Bothe, P. Pohl, and J. Schmidt, Journal of Applied Physics 98, 083509 (2005).

${ }^{15}$ G. W. Ludwig and H. H. Woodbury, in Solid State Physics, Vol. 13, edited by F. Seitz and D. Turnbull (Academic Press, New York, 1962) p. 223.

${ }^{16}$ W. Gehlhoff, K. Irmscher, and J. Kreissl, in New Developments in Semiconductor Physics, Lecture Notes in Physics, Vol. 301, edited by G. Ferenczi and F. Beleznay (Springer Berlin Heidelberg, 1988) pp. 262-267.

${ }^{17}$ J.-M. Spaeth, S. Martini, and S. Greulich-Weber, Semiconductor Science and Technology 13, 725 (1998).

${ }^{18} \mathrm{G}$. Zoth and W. Bergholz, Journal of Applied Physics 67, 6764 (1990).

${ }^{19}$ D. Gilles, W. Schröter, and W. Bergholz, Phys. Rev. B 41, 5770 (1990).

${ }^{20}$ G. Langouche, Hyperfine Interactions 72, 215 (1992).

${ }^{21}$ G. Weyer, S. Degroote, M. Fanciulli, V. N. Fedoseyev, G. Langouche, V. I. Mishin, A.-M. V. Bavel, A. Vantomme, and the ISOLDE Collaboration, Materials Science Forum 258-263, 437 (1997). 
${ }^{22}$ G. Weyer, A. Burchard, M. Fanciulli, V. Fedoseyev, H. Gunnlaugsson, V. Mishin, and R. Sielemann, Physica B: Condensed Matter 273-274, 363 (1999).

${ }^{23}$ Y. Yoshida, Y. Kobayashi, A. Yoshida, X. Diao, S. Ogawa, K. Hayakawa, K. Yukihira, F. Shimura, and F. Ambe, Hyperfine Interactions 141-142, 157 (2002).

${ }^{24}$ Y. Yoshida, S. Ogawa, and K. Arikawa, Physica B: Condensed Matter 340-342, 605 (2003).

${ }^{25}$ S. K. Estreicher, M. Sanati, and N. Gonzalez Szwacki, Phys. Rev. B 77, 125214 (2008).

${ }^{26}$ Y. Yoshida, Y. Suzuki, A. Matsushita, K. Suzuki, and K. Sakata, Physica B: Condensed Matter 401-402, 167 (2007).

${ }^{27}$ E. Weber and H. G. Riotte, Journal of Applied Physics 51, 1484 (1980).

${ }^{28}$ Y. Yoshida and G. Langouche, eds., Mössbauer Spectroscopy, Tutorial Book (Springer Berlin, Berlin Heidelberg, 2013).

${ }^{29}$ N. N. Greenwood and T. C. Gibb, Mössbauer spectroscopy (Chapman and Hall London, 1971).

${ }^{30} \mathrm{P}$. Gütlich, Zeitschrift für anorganische und allgemeine Chemie 638, 15 (2012).

${ }^{31}$ Y. Kobayashi, Y. Yoshida, A. Yoshida, Y. Watanabe, K. Hayakawa, K. Yukihira, F. Shimura, and F. Ambe, Hyperfine Interactions 126, 417 (2000).

${ }^{32}$ G. Weyer, Hyperfine Interactions 129, 371 (2000).

${ }^{33}$ H. P. Gunnlaugsson, M. Fanciulli, M. Dietrich, K. BharuthRam, R. Sielemann, G. Weyer, I. collaboration, and others, Nuclear Instruments and Methods in Physics Research Section B: Beam Interactions with Materials and Atoms 186, 55 (2002).

${ }^{34}$ H. P. Gunnlaugsson, G. Weyer, M. Dietrich, M. Fanciulli, K. Bharuth-Ram, R. Sielemann, t. ISOLDE Collaboration, and others, Physica B: Condensed Matter 340, 537 (2003).

${ }^{35}$ G. Weyer, H. P. Gunnlaugsson, M. Dietrich, H. Fynbo, K. Bharuth-Ram, and the ISOLDE Collaboration, The European Physical Journal Applied Physics 27, 317 (2004).

${ }^{36}$ K. Bharuth-Ram, H. P. Gunnlaugsson, R. Mantovan, V. V. Naicker, D. Naidoo, R. Sielemann, G. Weyer, T. Aigne, and ISOLDE Collaboration, Hyperfine Interactions 184, 207 (2008).

${ }^{37}$ H. P. Gunnlaugsson, K. Bharuth-Ram, M. Dietrich, M. Fanciulli, H. O. U. Fynbo, and G. Weyer, Hyperfine Interactions 169, 1319 (2006).

${ }^{38}$ K. Bharuth-Ram, M. Hartick, E. Kankeleit, C. Dorn, P. Held, R. Sielemann, L. Wende, J. Kübler, and J. P. F. Sellschop, Physical Review B 58, 8955 (1998).

${ }^{39}$ M. Elzain, S. H. Al-Harthi, A. Gismelseed, A. Al-Rawas, A. Yousif, H. Widatallah, and M. Al-Barwani, Hyperfine Interactions 226, 281 (2014).

${ }^{40}$ Y. Abreu, C. Cruz, I. Piñera, A. Leyva, A. Cabal, P. Van Espen, and N. Van Remortel, Physica B: Condensed Matter 445, 1 (2014).

${ }^{41}$ J. Kübler, A. E. Kumm, H. Overhof, P. Schwalbach, M. Hartick, E. Kankeleit, B. Keck, L. Wende, and R. Sielemann, Zeitschrift für Physik B Condensed Matter 92, 155 (1993).

${ }^{42}$ H. P. Gunnlaugsson, G. Weyer, M. Dietrich, ISOLDE collaboration, M. Fanciulli, K. Bharuth-Ram, and R. Sielemann, Applied Physics Letters 80, 2657 (2002).

${ }^{43}$ Y. Yoshida, Y. Ino, and K. Tanaka, Solid State Phenomena 242, 211 (2016).

${ }^{44}$ P. Hohenberg and W. Kohn, Phys. Rev. 136, B864 (1964).

${ }^{45}$ W. Kohn and L. J. Sham, Phys. Rev. 140, A1133 (1965).

${ }^{46}$ J. P. Perdew, K. Burke, and M. Ernzerhof, Phys. Rev. Lett. 77, 3865 (1996)

${ }^{47}$ J. P. Perdew, K. Burke, and M. Ernzerhof, Phys. Rev. Lett. 78, 1396 (1997)

${ }^{48}$ See http://elk. sourceforge.net/ for a description of the features and documentation of the ELK code.

${ }^{49}$ G. Kresse and J. Hafner, Phys. Rev. B 47, 558 (1993).

${ }^{50}$ G. Kresse and J. Hafner, Phys. Rev. B 49, 14251 (1994).

${ }^{51}$ G. Kresse and J. Furthmüller, Phys. Rev. B 54, 11169 (1996).

${ }^{52}$ G. Kresse and J. Furthm'uller, Comput. Mater. Sci. 6, 15 (1996).

${ }^{53}$ P. E. Blöchl, Phys. Rev. B 50, 17953 (1994).
${ }^{54}$ G. Kresse and D. Joubert, Phys. Rev. B 59, 1758 (1999).

${ }^{55}$ H. J. Monkhorst and J. D. Pack, Phys. Rev. B 13, 5188 (1976).

${ }^{56}$ O. Madelung, ed., Semiconductors - Basic Data, 2nd ed. (Springer-Verlag, Berlin Heidelberg, 1996).

${ }^{57}$ G. K. H. Madsen, P. Blaha, K. Schwarz, E. Sjöstedt, and L. Nordström, Phys. Rev. B 64, 195134 (2001).

${ }^{58}$ D. J. Singh and L. Nordstrom, Planewaves, Pseudopotentials, and the $L A P W$ method, 2nd ed. (Springer US, New York, 2006).

${ }^{59}$ O. K. Andersen, Phys. Rev. B 12, 3060 (1975).

${ }^{60}$ E. G. Moroni, W. Wolf, J. Hafner, and R. Podloucky, Phys. Rev. B 59, 12860 (1999).

${ }^{61}$ A. R. Bodmer, Proceedings of the Physical Society. Section A 66, 1041 (1953).

${ }^{62}$ D. A. Shirley, Reviews of Modern Physics 36, 339 (1964).

${ }^{63}$ I. Angeli, Atomic Data and Nuclear Data Tables 87, 185 (2004).

${ }^{64}$ L. Mauger, M. S. Lucas, J. A. Muñoz, S. J. Tracy, M. Kresch, Y. Xiao, P. Chow, and B. Fultz, Phys. Rev. B 90, 064303 (2014).

${ }^{65}$ J. ichi Tani, M. Takahashi, and H. Kido, Physica B: Condensed Matter 405, 2200 (2010).

${ }^{66} \mathrm{H}$. Reuther and G. Behr, Hyperfine Interactions 141-142, 435 (2002).

${ }^{67}$ P. Dufek, P. Blaha, and K. Schwarz, Phys. Rev. Lett. 75, 3545 (1995).

${ }^{68}$ U. D. Wdowik and K. Ruebenbauer, Physical Review B 76 (2007), 10.1103/PhysRevB.76.155118.

${ }^{69}$ J. E. Northrup and S. B. Zhang, Phys. Rev. B 47, 6791 (1993).

${ }^{70}$ W. M. Haynes, ed., CRC Handbook of Chemistry and Physics, 95th ed. (CRC Press, Boca Raton, Florida, 2014).

${ }^{71}$ A. Resende, R. Jones, S. Oberg, and P. R. Briddon, Phys. Rev. Lett. 82, 2111 (1999).

${ }^{72}$ M. J. Shaw, J. P. Goss, and P. R. Briddon, in Theory of Defects in Semiconductors, Topics in Applied Physics, Vol. 104, edited by D. A. Drabold and S. K. Estreicher (Springer Berlin Heidelberg, 2007) pp. 69-94.

${ }^{73}$ D. Mathiot and S. Hocine, Journal of Applied Physics 66, 5862 (1989).

${ }^{74}$ V. Kolkovsky, L. Scheffler, and J. Weber, physica status solidi (c) 9, 1996 (2012).

${ }^{75}$ L. Scheffler, V. Kolkovsky, and J. Weber, Journal of Applied Physics 117, 045713 (2015).

${ }^{76}$ S. D. Brotherton, P. Bradley, and A. Gill, Journal of Applied Physics 57, 1941 (1985).

${ }^{77}$ A. A. Istratov, H. Hieslmair, C. Flink, T. Heiser, and E. R. Weber, Applied Physics Letters 71, 2349 (1997).

${ }^{78}$ N. Yarykin and J. Weber, Physical Review B (2011), 10.1103/PhysRevB.83.125207.

${ }^{79}$ M. Acet, H. Zähres, E. F. Wassermann, and W. Pepperhoff, Phys. Rev. B 49, 6012 (1994).

${ }^{80}$ Y. Mori, H. Nakano, G. Sakane, G. Aquilanti, H. Udono, and K. Takarabe, physica status solidi (b) 246, 541 (2009).

${ }^{81} \mathrm{P}$. Thompson, J. J. Reilly, and J. M. Hastings, Journal of Applied Crystallography 22, 256 (1989).

${ }^{82}$ E. V. Mielczarek and W. P. Winfree, Phys. Rev. B 11, 1026 (1975).

${ }^{83}$ V. Niculescu, K. Raj, J. I. Budnick, T. J. Burch, W. A. Hines, and A. H. Menotti, Phys. Rev. B 14, 4160 (1976).

${ }^{84}$ K. Hamaya, T. Murakami, S. Yamada, K. Mibu, and M. Miyao, Phys. Rev. B 83, 144411 (2011).

${ }^{85}$ W. Miiller, J. M. Tomczak, J. W. Simonson, G. Smith, G. Kotliar, and M. C. Aronson, Journal of Physics: Condensed Matter 27, 175601 (2015).

${ }^{86}$ H. Reuther, G. Behr, and A. Teresiak, Journal of Physics: Condensed Matter 13, L225 (2001).

${ }^{87}$ Y. Dusausoy, J. Protas, R. Wandji, and B. Roques, Acta Crystallographica Section B 27, 1209 (1971).

${ }^{88}$ M. Fanciulli, C. Rosenblad, G. Weyer, A. Svane, N. E. Christensen, and H. von Känel, Phys. Rev. Lett. 75, 1642 (1995).

${ }^{89}$ L. Pauling and A. M. Soldate, Acta Crystallographica 1, 212 (1948). 
${ }^{90}$ M. Fanciulli, A. Zenkevich, I. Wenneker, A. Svane, N. E. Christensen, and G. Weyer, Phys. Rev. B 54, 15985 (1996).

${ }^{91} \mathrm{M}$. Balkanski, P. Moch, and G. Parisot, The Journal of Chemical Physics 44, 940 (1966).

${ }^{92}$ G. K. Wertheim and D. N. E. Buchanan, Phys. Rev. 161, 478 (1967).

${ }^{93}$ M. Leblanc, J. Pannetier, G. Ferey, and R. de Pape, Revue de Chimie Minerale 22, 107 (1985).

${ }^{94}$ G. K. Wertheim, H. J. Guggenheim, and D. N. E. Buchanan, Phys. Rev. 169, 465 (1968).

${ }^{95}$ M. K. Wilkinson, J. W. Cable, E. O. Wollan, and W. C. Koehler, Phys. Rev. 113, 497 (1959).

${ }^{96}$ E. Pfletschinger, Zeitschrift für Physik 209, 119 (1968).

${ }^{97}$ C. Kittel, Introduction to Solid State Physics, 8th ed. (John Wiley \& Sons, Inc., New York, 2005).

${ }^{98}$ D. A. Papaconstantopoulos, Phys. Rev. B 11, 4801 (1975).

${ }^{99}$ A. Ionescu, C. A. F. Vaz, T. Trypiniotis, C. M. Gürtler, H. García-Miquel, J. A. C. Bland, M. E. Vickers, R. M. Dalgliesh, S. Langridge, Y. Bugoslavsky, Y. Miyoshi, L. F. Cohen, and K. R. A. Ziebeck, Phys. Rev. B 71, 094401 (2005).

${ }^{100}$ V. A. Niculescu, T. J. Burch, and J. I. Budnick, Journal of Magnetism and Magnetic Materials 39, 223 (1983).

${ }^{101}$ D. Leong, M. Harry, K. J. Reeson, and K. P. Homewood, Nature 387, 686 (1997)

${ }^{102}$ A. B. Filonov, D. B. Migas, V. L. Shaposhnikov, N. N. Dorozhkin, G. V. Petrov, V. E. Borisenko, W. Henrion, and H. Lange, Journal of Applied Physics 79, 7708 (1996).

${ }^{103}$ M. Fanciulli, C. Rosenblad, G. Weyer, A. Svane, N. E. Christensen, H. von Känel, and C. O. Rodriguez, Journal of Physics: Condensed Matter 9, 1619 (1997).

${ }^{104}$ H. Watanabe, H. Yamamoto, and K. ichi Ito, J. Phys. Soc. Jpn. 18, 995 (1963).

${ }^{105}$ S. López-Moreno, A. H. Romero, J. Mejía-López, A. Muñoz, and I. V. Roshchin, Phys. Rev. B 85, 134110 (2012).

${ }^{106}$ J. Strempfer, U. Rütt, S. P. Bayrakci, T. Brückel, and W. Jauch, Phys. Rev. B 69, 014417 (2004).

${ }^{107}$ E. O. Wollan, H. R. Child, W. C. Koehler, and M. K. Wilkinson, Phys. Rev. 112, 1132 (1958).

${ }^{108}$ E. Weber, Applied Physics A 30, 1 (1983).
${ }^{109}$ G. W. Ludwig and H. H. Woodbury, Phys. Rev. 117, 1286 (1960).

${ }^{110} \mathrm{H}$. Weihrich and H. Overhof, Phys. Rev. B 54, 4680 (1996).

${ }^{111}$ M. Sanati, N. G. Szwacki, and S. K. Estreicher, Phys. Rev. B 76, 125204 (2007).

${ }^{112}$ G. W. Ludwig and H. H. Woodbury, Phys. Rev. Lett. 5, 98 (1960).

${ }^{113}$ A. I. Liechtenstein, V. I. Anisimov, and J. Zaanen, Phys. Rev. B 52, R5467 (1995).

${ }^{114}$ H. Katayama-Yoshida and A. Zunger, Phys. Rev. B 31, 7877 (1985).

${ }^{115}$ S. Zhao, L. V. C. Assali, J. F. Justo, G. H. Gilmer, and L. C. Kimerling, Journal of Applied Physics 90, 2744 (2001).

${ }^{116}$ H. Lemke, physica status solidi (a) 64, 215 (1981).

${ }^{117}$ S. Ghatnekar-Nilsson, M. Kleverman, P. Emanuelsson, and H. G. Grimmeiss, Semiconductor Science and Technology 8, 1857 (1993)

${ }^{118}$ H. Gunnlaugsson, K. Bharuth-Ram, M. Dietrich, M. Fanciulli, H. Fynbo, and G. Weyer, Hyperfine Interactions 169, 1315 (2006).

${ }^{119}$ W. Bergholz, Physica B + C 116, 312 (1983).

${ }^{120}$ G. D. Watkins, "Deep centers in semiconductors," (Gordon and Breach Science Publishers, New York, 1992) Chap. 3, p. 177, 2nd ed.

${ }^{121}$ A. Zunger and U. Lindefelt, Phys. Rev. B 26, 5989 (1982).

${ }^{122}$ F. Beeler, O. K. Andersen, and M. Scheffler, Phys. Rev. Lett. 55, 1498 (1985).

${ }^{123}$ P. Kaminski, R. Kozlowski, A. Jelenski, T. Mchedlidze, and M. Suezawa, Japanese Journal of Applied Physics 42, 5415 (2003).

${ }^{124} \mathrm{~S}$. Tanaka and H. Kitagawa, Japanese Journal of Applied Physics 34, L721 (1995).

${ }^{125}$ G. Henkelman, B. P. Uberuaga, and H. Jónsson, J. Chem. Phys. 113, 9901 (2000).

${ }^{126}$ G. Henkelman and H. Jónsson, J. Chem. Phys. 113, 9978 (2000).

${ }^{127}$ T. Mchedlidze and M. Suezawa, Physica B: Condensed Matter 324, 188 (2002).

${ }^{128}$ S. H. Muller, G. M. Tuynman, E. G. Sieverts, and C. A. J. Ammerlaan, Phys. Rev. B 25, 25 (1982).

${ }^{129}$ C. K. Tang, L. Vines, V. P. Markevich, B. G. Svensson, and E. V. Monakhov, Journal of Applied Physics 113, 044503 (2013). 